2 Cytoplasmic RNA sensors and their interplay with RNA-

3 binding partners in innate antiviral response: Theme

4 and variations

5

6 CHI-PING CHAN and DONG-YAN JIN

7

8 
21 Sensing of pathogen-associated molecular patterns including viral RNA by innate immunity represents the first line of defense against viral infection. In addition to RIG-I-like receptors and NOD-like receptors, several other RNA sensors are known to mediate innate antiviral response in the cytoplasm. Double-stranded RNA-binding protein PACT interacts with prototypic RNA sensor RIG-I to facilitate its recognition of viral RNA and induction of host interferon response, but variations of this theme are seen when the functions of RNA sensors are modulated by other RNA-binding proteins to impinge on antiviral defense, proinflammatory cytokine production and cell death programs. Their discrete and coordinated actions are crucial to protect the host from infection. In this review, we will focus on cytoplasmic RNA sensors with an emphasis on their interplay with RNA-binding partners. Classical sensors such as RIG-I will be briefly reviewed. More attention will be brought to the new insights on how RNA-binding partners of RNA sensors modulate innate RNA sensing and how viruses perturb the functions of RNA-binding partners. 


\section{INTRODUCTION}

37 Innate antiviral response constitutes the first line of host defense against viral invasion. Upon 38 viral infection, foreign molecular features, called pathogen-associated molecular patterns 39 (PAMPs), are produced and sensed by pattern-recognition receptors (PRRs) of the host cells.

40 Particularly, the sensing of non-self viral RNAs, as one major PAMP, by host PRRs such as RIG-

41 I in the cytoplasm (Yoneyama et al. 2004), represents a pivotal step to elicit complex proinflammatory and immuno-regulatory reactions that protect the host. RIG-I is a DEXD/Hbox helicase evolutionarily related to Dicer, an RNase III that cleaves double-stranded RNA (dsRNA) and pre-microRNA (pre-miRNA) (Luo et al. 2013). Whereas the optimal function of

Dicer requires dsRNA-binding proteins TRBP and PACT (Chendrimada et al. 2005; Lee et al. 2006; Kok et al. 2007), RIG-I also co-opts PACT to activate interferon (IFN) production upon recognition of viral RNA (Kok et al. 2011). The interaction between RIG-I and PACT is highly representative of the trend in which RNA sensors engage RNA-binding proteins to facilitate ligand recognition and selection. In addition, the RNA-binding proteins might also adapt RIGI signalling to other RNA-activated pathways such as miRNA biogenesis and PKR activation (Heyam et al. 2015; Hur 2019). Variations of the theme are also seen when different types of RNA-binding proteins are recruited to modulate the functions of RNA sensors. Notably, some of these interactions between RNA sensors and their RNA-binding partners are evolutionarily conserved among different species.

55 In this review, we will provide an overview of cytoplasmic RNA sensors including RIG-Ilike receptors (RLRs), NOD-like receptors (NLRs) and other newly identified sensors (Figure 1).

57 For a more detailed discussion of RIG-I and other RNA sensors, we refer the readers to other recent reviews (Brisse and Ly 2019; Hur 2019; Liu and Gack 2020; Thoresen et al. 2021). Our 
60 the functions of RNA sensors. Examples will be used to demonstrate the functional interplay

61 between the RNA sensors and their RNA-binding partners. Comparisons will be made with 62 the roles of dsRNA-binding partners in Dicer function, where more mechanistic insights are 63 available. Finally, we will also summarize viral strategies to overturn innate RNA sensing by 64 targeting the RNA-binding partners of sensors.

\section{RLRs}

RLRs, being expressed in most cell types, are key players in sensing immunostimulatory RNA of either viral or host origins and triggering subsequent innate immune signalling. RLRs are a group of PRRs encompassing three cytoplasmic RNA sensors known to have distinct roles and substrate specificity. In addition to its prototypic member RIG-I, the group also includes MDA5 and LGP2. Despite a recent report demonstrating the existence of nuclear-localized RIG-I (Liu et al. 2018), RLRs predominantly localize to the cytoplasm. Structurally, RIG-I and MDA5 are more similar in their domain architectures. They both harbour tandem caspase activation and recruitment domains (CARDs) at the $\mathrm{N}$-terminus for signal transduction, a central RNA helicase core consisting of two RecA-like helicase domains for RNA sensing, and a C-terminal repressor domain (CTD) for activity regulation (Chow et al. 2018). In contrast, LGP2 contains only the helicase domain and CTD but not the CARDs. Due to the lack of CARDs, LGP2 is thought to be signalling-incompetent and mainly functions to regulate RIG-I and MDA5 signalling (Bruns and Horvath 2015).

Upon viral infection, RLRs recognize and bind to virus-derived RNA ligands leading to a conformational change to expose the active CARDs for their oligomerization and subsequent association with the mitochondrial adaptor protein MAVS (Fan and Jin 2019). Upon 
stimulation by RIG-I or MDA5, MAVS forms the large prion-like polymers along the outer mitochondrial membrane. The MAVS polymers then recruit TRAF2, TRAF5 and TRAF6 for activation of TBK1 and the IKK family of serine kinases (Liu et al. 2013). These kinases in turn activate IRF3 and NF-KB to drive the transcription of various antiviral genes such as IFN- $\beta$. Secreted IFN- $\beta$ acts in both autocrine and paracrine fashions on the infected and neighbouring cells, respectively, via the IFNAR-JAK-STAT signalling pathway to initiate the antiviral programs (Schoggins 2019).

\section{RIG-I}

RIG-I, also known as DDX58, has a low basal expression level in most cells and is highly induced by IFNs (Matsumiya and Stafforini 2010). In the resting state, RIG-I remains in a closed inactive conformation with both the CTD and CARDs folded over the helicase domain. Upon recognition of RNA ligands, RIG-I hydrolyzes ATP and undergoes a conformational change, which allows for RIG-I oligomerization and its subsequent interaction with MAVS through the CARDs, thereby initiating downstream signalling for IFN production. Oligomeric RIG-I might assemble into a filamentous form only in the presence of RNA (Cadena et al. 2019). While RIG-I responds rapidly to trigger innate immune responses for effective antiviral defense, immune homeostasis also needs to be maintained during normal physiological conditions. Dysregulation of RIG-I activation could cause severe autoimmune diseases such as AicardiGoutières syndrome, systemic lupus erythematosus and other rare interferonopathies (Buers et al. 2016), thus the activity of RIG-I is tightly regulated through multiple mechanisms [reviewed in (Rehwinkel and Gack 2020)]. In brief, RIG-I activity could be regulated by posttranslational modifications (PTMs), interacting proteins, non-coding RNAs, and autophagy. Some of these important regulatory mechanisms will be briefly mentioned here and more 
details will be provided later. Firstly, multiple PTMs by various regulatory enzymes have been shown to regulate RIG-I activity. These include ubiquitination, ubiquitin-like protein conjugation, phosphorylation, acetylation, and deamidation. For one example, TRIM-like ubiquitin ligase RIPLET recognizes the RNA-bound oligomeric filament of RIG-I and catalyzes K63-linked ubiquitination of RIG-I to trigger its full activation (Cadena et al. 2019; Kato et al. 2021). The role of unanchored K63-linked poly-ubiquitin chain in the activation of RIG-I has also been suggested (Zeng et al. 2010). In another case, cooperative deamidation of RIG-I by herpesviral and cellular deamidases is a viral countermeasure to evade innate antiviral response (He et al. 2015; Huang et al. 2021). Secondly, various proteins interact with RIG-I to fulfill different functions in RIG-I activation, with a number of them serving as co-sensors for RNA. Particularly, PACT is one of the first dsRNA-binding proteins identified as a cellular interacting partner of RIG-I. Its direct binding to the CTD of RIG-I activates RIG-I and potentiates RIG-I-dependent type I interferon production (Kok et al. 2011). Thirdly, noncoding RNAs including long non-coding RNAs (IncRNA) and miRNAs are induced during viral infection to promote or dampen RIG-I signalling through a post-transcriptional mechanism. Whereas one IncRNA is thought to act as a scaffold for RIG-I activation (Lin et al. 2019), another IncRNA might serve as a decoy to pre-occupy all ligand-binding sites in RIG-I (Jiang et al. 2018). However, it remains to be seen whether these mechanisms might indeed operate in vivo. Lastly, autophagy has emerged as a negative regulatory process for RIG-I signalling through diverse mechanisms that include autophagy-dependent degradation of RIG-I or downstream signalling molecules. A recent report has identified a novel autophagic cargo receptor CCDC50, which is induced by viral infection and specifically recognizes K63-linked polyubiquitination in activated RIG-I and MDA5, thereby subjecting them to autophagic degradation (Hou et al. 2020). In addition, two LRRC family members LRRC25 and LRRC59 
have been shown to antagonize each other in targeting RIG-I to p62-dependent autophagic degradation (Xian et al. 2020).

RNA ligand specificity of RIG-I has been well characterized. RIG-I preferentially and optimally binds to short dsRNA of less than 300 base pairs (Kell and Gale 2015). The 5'triphosphate was initially identified as the molecular signature in RNA, which is sufficient for recognition by RIG-I for activation of IFN response (Hornung et al. 2006; Pichlmair et al. 2006). Later, short double-stranded base-paired RNA carrying 5'-triphosphate was further demonstrated as the essential molecular pattern for recognition by and activation of RIG-I (Schlee et al. 2009; Schmidt et al. 2009). Moreover, base-paired viral RNA bearing 5'diphosphate has also been shown to activate RIG-I-mediated IFN response (Goubau et al. 2014). Additionally, the lack of 2'-O-methylation at the 5'-terminal nucleotide of capped RNA was also shown to be the crucial determinant for RIG-I activation (Schuberth-Wagner et al. 2015). These molecular features, which are commonly found in RNA of viral origin but rarely present in host RNA, serve as crucial determinants for self and non-self discrimination by RIGI. Furthermore, RIG-I functions largely in a sequence-independent manner, but sequencespecific recognition of some viral genomes by RIG-I has also been noted (Saito et al. 2008; Schnell et al. 2012; Kell and Gale 2015). Natural agonists of RIG-I in virus-infected cells have been well described. Particularly, copy-back type defective-interfering RNAs derived from genomes of paramyxoviruses such as Sendai virus and measles virus are potent activators of RIG-I (Martinez-Gil et al. 2013). These viral RNAs contain a 5'-triphosphate and a long basepaired region (Xu et al. 2015; Ho et al. 2016; Mura et al. 2017). Other viral RNA ligands of RIGI include influenza A virus (IAV) panhandle structure (Liu et al. 2015), short dsRNA with 
overhanging 5'-triphosphate derived from arenavirus genome (Marq et al. 2011) and polyU/UC tract in the $3^{\prime}$ untranslated region of hepatitis C virus genome (Schnell et al. 2012). All these RNA agonists of RIG-I are potential innate immunostimulatory agents that might be further developed as antivirals or vaccine adjuvants. For example, they can serve as built-in adjuvants in mRNA vaccines.

RIG-I is involved in antiviral immune responses against almost all major virus families including both RNA and DNA viruses (Kell and Gale 2015; Zhao and Karijolich 2019). Indeed, many of these viruses are sensed by both RIG-I and MDA5 with differential potency. Viral infections that are thought to be detected by RIG-I include Adenoviridae (Minamitani et al. 2011), Arenaviridae (Habjan et al. 2008; Fan et al. 2010; Xing et al. 2015; Brisse et al., 2021), Coronaviridae (Li et al. 2010), Filoviridae (Edwards et al. 2016), Flaviviridae (Fredericksen et al. 2008; Saito et al. 2008; Nasirudeen et al. 2011; Schilling et al. 2020), Hepadnaviridae (Sato et al. 2015), Herpesviridae (Samanta et al. 2006; Xing et al. 2012; Chiang et al. 2018; Zhao et al. 2018), Orthomyxoviridae (Kato et al. 2006), Paramyxoviridae (Kato et al. 2006; Ikegame et al. 2010), Picornaviridae (Slater et al. 2010), Poxviridae (Myskiw et al. 2011), Reoviridae (Broquet et al. 2011; Sen et al. 2011), and Retroviridae (Solis et al. 2011; Berg et al. 2012).

\section{MDA5}

MDA5, also known as IFIH1, shows high structural similarity and some functional redundancy in pathogen recognition with RIG-I, but MDA5 indeed has distinct non-redundant functions (Brisse and Ly 2019). The molecular nature of MDA5 ligands is not well characterized but it has been shown that MDA5 preferentially binds to and is activated by long dsRNA of over 2 kilobase pairs (Kato et al. 2008; Rodriguez et al. 2014). Besides, higher-order structures like 
179 RNA branches in high-molecular-weight RNAs from infected cells have also been suggested to

180 serve as MDA5 agonists (Pichlmair et al. 2009; Rodriguez et al. 2014). Additionally, the lack of 2'-O-methylation in mRNA and the presence of specific AU-rich sequences in viral mRNA are recognized by MDA5 (Züst et al. 2011; Runge et al. 2014). Upon binding with RNA, MDA5 oligomerizes and forms filaments (Berke and Modis 2012).

With a distinct agonist preference compared to RIG-I, MDA5 plays differential roles in the recognition of viral infections. Although MDA5 is a major sensor of viral RNA in the cases of certain positive-sense single-stranded RNA viruses, this cannot be generalized to all RNA viruses of the same group. Indeed, MDA5 possesses broad antiviral roles against many viruses. Viral infections that are detected by MDA5 include Coronaviridae (Li et al. 2010), Filoviridae (Edwards et al. 2016), Flaviviridae (Fredericksen et al. 2008; Nasirudeen et al. 2011)), Hepadnaviridae (Lu and Liao 2013), Herpesviridae (Xing et al. 2012; Zhao et al. 2018), Paramyxoviridae (Yount et al. 2008; Ikegame et al. 2010), Picornaviridae (Kato et al. 2006; Wang et al. 2009; Slater et al. 2010; Feng et al. 2012), Poxviridae (Myskiw et al. 2011), and Reoviridae (Broquet et al. 2011; Sen et al. 2011).

(1)

Similar to mutations in RIG-I, MDA5 mutations in humans are associated with rare interferonopathies such as Aicardi-Goutières syndrome (Buers et al. 2016). On the other hand, autoantibodies against MDA5 have been found in dermatomyositis, an idiopathic inflammatory myopathy (Kurtzman and Vleugels 2018). Hence, MDA5 activity has to be tightly regulated via multiple mechanisms. MDA5 is regulated by several types of PTMs including phosphorylation, ubiquitination and sumoylation (Rehwinkel and Gack 2020). Particularly, ubiquitin ligase TRIM65 specifically recognizes RNA-bound MDA5 filaments to catalyze K63- 
linked ubiquitination and activation of MDA5 (Kato et al. 2021). Similar to RIG-I, unanchored

but longer K63-linked polyubiquitin chain is thought to trigger oligomerisation and activation of MDA5 (Song et al. 2021). Besides, different MDA5 interacting partners are also involved in MDA5 regulation. One recently identified MDA5 binding partner named ZFYVE1, a zinc finger protein containing a FYVE domain and capable of binding to dsRNA, is a negative regulator of MDA5, but not RIG-I (Zhong et al. 2020b). Notably, increasing evidence suggests the third RLR member, LGP2, as an important positive regulator of MDA5 in RNA recognition (Rodriguez et al. 2014; Duic et al. 2020). Some RNA-binding proteins reviewed below have also been suggested to regulate MDA5 activity, for example, by serving as co-sensors for MDA5. As such, PACT functions as a coactivator of MDA5 by promoting MDA5 oligomerization upon dsRNAinduced activation (Lui et al. 2017). Furthermore, IncRNA ITPRIP-1 has been shown to interact with MDA5 to stabilize its binding to viral RNAs and facilitate its oligomerization for IFN signalling (Xie et al. 2018b). Again, autophagy may as well play a role in MDA5 regulation through degradation of MDA5 or downstream signalling molecules (Hou et al. 2020). Whereas most of the aforementioned regulatory mechanisms operate on both RIG-I and MDA5, some of them, such as those involving TRIM65 and ZFYVE1, are specific to MDA5. It is also noteworthy that RIG-I and MDA5 share other features required for activation with other innate signal transducers such as MAVS, including K63-linked ubiquitination, oligomerization made to facilitate ligand recognition and propagate downstream signalling.

In addition to the induction of IFN production, activated RIG-I and MDA5 can also trigger other effector functions of innate antiviral response, including NF- $\kappa B$ activation, 226 inflammasome assembly, pyroptosis, apoptosis and necroptosis (Poeck and Ruland 2012; 
227 Maelfait et al. 2020). RIG-I signalling is known to be adapted to NF- $\kappa B$ activation via CARD9 228 and to inflammasome activation either directly or via MAVS (Poeck et al. 2010; Franchi et al. 229 2014). Pyroptosis is a result of RIG-I-mediated inflammasome activation (Lupfer et al. 2015). 230 Induction of apoptosis by RIG-I and MDA5 is mediated through a unique mechanism known 231 as RLR-induced IRF3-mediated pathway of apoptosis (RIPA), during which TRAF2, TRAF6 and 232 linear ubiquitin chain assembly complex (LUBAX) are recruited to modify IRF3, leading to its 233 subsequent translocation with Bax to mitochondria (Chattopadhyay et al. 2010; 234 Chattopadhyay et al. 2016). Furthermore, RIG-I-dependent IFN response also promotes 235 RIPK3-mediated necroptosis (Brault et al. 2018; Dunker et al. 2021). In many cases, the 236 activation of inflammasome and cell death program might either exert a protective role by 237 eliminating the virus-infected cells or facilitate virus dissemination and spread by releasing a 238 large number of virion particles.

LGP2

241 LGP2, also known as DHX58, lacks the CARDs, thus it is widely accepted that LGP2 is signalling242 incompetent and functions in innate immune responses mainly through regulating RIG-I and 243 MDA5 activity (Onomoto et al. 2021). Various reports have implicated LGP2 in antiviral innate 244 responses with apparently opposing roles, by serving as an inhibitor of RIG-I signalling and an 245 activator of MDA5 signalling. For the RIG-I signalling pathway, LGP2 has been suggested to 246 function as a feedback inhibitor to repress RIG-I activation and antiviral response through 247 multiple mechanisms. With a stronger RNA binding affinity than RIG-I and MDA5, LGP2 248 inhibits RIG-I activation by sequestration of RNA (Rothenfusser et al. 2005; Rodriguez et al. 249 2014). Besides, LGP2 also interacts through its CTD with RIG-I and MAVS to hinder RIG-I 250 oligomerization and kinase recruitment by MAVS, respectively, to negatively regulate antiviral 
251 IFN signalling (Komuro and Horvath 2006; Saito et al. 2007; Rodriguez et al. 2014). However,

252 a later study has shown that CTD of LGP2 is dispensable for inhibiting RIG-I signalling and 253 suggested that the inhibition is mediated through the interaction of LGP2 with TRIM25 to 254 suppress ubiquitination of RIG-I which is required for RIG-I activation (Quicke et al. 2019). 255 Contrary to this, characterization of $\operatorname{Lgp} 2^{-/}$mice has revealed a positive regulatory role of 256 LGP2 on both RIG-I and MDA5 signalling (Satoh et al. 2010). The controversy remains as to whether LGP2 stimulates or suppresses RIG-I-dependent activation of type I IFN production. 258 Plausibly, it might vary on different RNA ligands, at different subcellular compartments, during different phases of viral infection and in the presence of different co-sensors such as PACT (Sanchez David et al. 2019). Indeed, in the absence of RNA, LGP2 has been found to interact with MAVS in microsomes to prevent the latter from engaging RIG-I in resting cells. However, upon dsRNA treatment or viral infection, LGP2 rapidly releases MAVS and relocalizes to mitochondria, augmenting RIG-I and MDA5 signalling (Esser-Nobis et al. 2020). Further investigations are required to determine under what physiological conditions LGP2 might positively and negatively modulate RIG-I signalling.

A consensus on the stimulatory effect of LGP2 on MDA5 signalling has emerged in the literature (Bruns et al. 2014). Particularly, loss of LGP2 increases susceptibility and reduces IFN response to several RNA viruses including encephalomyocarditis virus (EMCV) and 270 poliovirus, which are primarily sensed by MDA5 (Satoh et al. 2010). LGP2, with no signalling capability, is believed to work by binding to and forming a complex with RNA for subsequent 272 relaying to MDA5 to trigger IFN signalling. This resembles the role of PACT and the idea is supported by the finding that MDA5-stimulatory RNA in EMCV-infected cells is identified in LGP2 complex rather than in MDA5 complex (Deddouche et al. 2014). Indeed, biochemical 
analysis indicates the requirement of ATP hydrolysis for RNA recognition and innate immune signalling by LGP2. Through this mechanism, LGP2 synergizes with MDA5 to engage different RNA species leading to subsequent activation of MDA5 (Bruns et al. 2013). This also explains the essentiality of ATPase activity of LGP2 in its synergistic effect with MDA5, which contrasts with the enzymatic activity-independent regulation of RIG-I by LGP2. Again, the roles of LGP2 in this scenario are similar to those of PACT. Indeed, the interaction between LGP2 and PACT is critical for LGP2-mediated regulation of both RIG-I and MDA5 signalling. It is thought that PACT functions as a key determining factor in differential regulation of RIG-I and MDA5 by LGP2 (Sanchez David et al. 2019). Upon binding with RNA, LGP2 also forms filaments and serves as the nucleator and essential partner for formation of MDA5 filaments (Uchikawa et al. 2016; Duic et al. 2020). LGP2 has been found to form hetero-oligomers with MDA5 and induces significant conformational change of MDA5 to facilitate its activation (Duic et al. 2020). Comparative analysis of RLR-bound RNA ligands in measles virus-infected cells indicates preferential recognition of nucleoprotein-coding region by LGP2 and MDA5, distinct with defective-interfering RNA recognized by RIG-I (Sanchez David et al. 2016).

\section{NLRs}

NLRs represent a specialized group of intracellular PRRs responsible for recognizing PAMPs and danger-associated molecular patterns (DAMPs) during infection, environmental insults or cellular stresses (Carneiro et al. 2008; Corridoni et al. 2014). NLRs typically have a threedomain protein structure, which includes an N-terminal effector domain, a central NOD (also called NACHT) domain and a C-terminal leucine-rich repeat (LRR) domain (Corridoni et al. 2014). While all NLR members harbour the common characteristic NOD domain essential for dNTPase activity and NLR protein oligomerization, the 22 known human NLRs can be further 
classified into five subfamilies according to the $\mathrm{N}$-terminal effector domains. The five subfamilies include NLRA (A for acidic transactivating domain), NLRB (B for BIRs or baculovirus inhibitor of apoptosis protein repeats domain), NLRC (C for CARD or caspase activation and recruitment domain), NLRP (P for PYD or pyrin domain) and NLRPX, which has no homology to any other NLR proteins (Corridoni et al. 2014; Zheng et al. 2021). With different effector domains, NLR proteins bind to distinct downstream signalling proteins leading to different outcomes. The LRR domain in NLR proteins is responsible for ligand binding and is also essential for intramolecular interaction with the NOD domain to prevent signalling under the resting state. Upon ligand recognition by the LRR domain, conformational changes will occur in NLRs that induce NLR oligomerization and the exposure of effector domains for protein recruitment and activation of downstream signalling cascades (Liu and Gack 2020). responses. A considerable number of NLR members are known to serve as scaffold proteins for inflammasome complex formation to promote maturation and secretion of interleukin $1 \beta$ antiviral responses (Sabbah et al. 2009; Wang et al. 2015; Zhu et al. 2017).

NOD2

NOD2, also known as NLRC2, has been implicated in interferon (IFN) response against singlestranded RNA (ssRNA) and human respiratory syncytial virus (RSV) infection (Sabbah et al. 2009). This provides the first evidence for NLR involvement in innate antiviral response as a 
direct viral RNA sensor. NOD2 recognizes and interacts with viral ssRNA to facilitate virusinduced IFN production. Virus-induced NOD2-mediated IFN response is MAVS-dependent.

325 The enhanced RSV pathogenesis and greater viral susceptibility in NOD2-deficient mice provide further support to the physiological importance of NOD2 in antiviral defense. Besides,

327 the significance of NOD2 has also been noted during infection with other viruses including IAVs and parainfluenza viruses (Lupfer et al. 2014). However, NOD2 expression has also been shown to promote Zika virus replication possibly through inhibition of IFN response. In addition, inhibition of NOD2 with a small-molecule compound exhibits broad-spectrum antiviral activity against multiple RNA viruses including dengue virus, alphaviruses, enteroviruses and SARS-CoV-2, which is mediated at least in part through augmented IFN response (Limonta et al. 2021). It remains to be clarified whether NOD2 has proviral and antiviral activity against different RNA viruses.

\section{NLRP1}

NLRP1, also called NALP1, was the first characterized sensor for triggering inflammasome activation (Martinon et al. 2002), but its physiological role as an RNA sensor against viral infection has only been identified very recently (Bauernfried et al. 2021). NLRP1 is a widely expressed protein with the highest abundance in epithelial tissues. Gain-of-function NLRP1 mutations in patients cause inflammatory phenotypes in the skin and respiratory tract (Zhong 342 et al. 2016; Drutman et al. 2019), which is consistent with its crucial role in non-selfrecognition. Human NLRP1 is stimulated by long dsRNA during Semliki Forest virus infection in keratinocytes to trigger inflammasome activation (Bauernfried et al. 2021). Human NLRP1 binds dsRNA with high affinity primarily through its leucine-rich repeat domain. Upon binding to dsRNA, ATPase activity of NLRP1 is activated, likely through a conformational change that 
347 is important for its oligomerization and formation of inflammasome complex. This 348 subsequently leads to IL-1 $1 \beta$ maturation and the induction of pyroptosis. Thus, human NLRP1 349 plays an important role in host defense by serving as a sensor of dsRNA for initiating 350 inflammasome activation.

351

352

\section{NLRP3}

NLRP3, also called cryopyrin or NALP3, is one of the most studied NLRs and has long been known to mediate immune responses against diverse PAMPs and DAMPs through the formation of inflammasome complex with ASC and pro-caspase-1 to promote the secretion of proinflammatory cytokines (Kanneganti et al. 2006). Extremely diversified signals such as crystals, extracellular ATP, nucleic acids, bacteria, fungi and viruses are all capable of activating the NLRP3 inflammasome (Da Costa et al. 2019). The mechanistic details for activation of NLRP3 inflammasome remain to be dissected. Particularly, multiple mechanisms for the sensing of RNA virus infection by NLRP3 have been proposed. DHX33, a DExD/H-box helicase, functions as an upstream RNA sensor for NLRP3 activation (Mitoma et al. 2013). Upon stimulation with RNA, DHX33 interacts with NLRP3 to initiate NLRP3 oligomerization and trigger the inflammasome activation cascade. Other mechanisms for NLRP3 activation include sensing of ion flux by viroporins such as IAV M2 channel (Ichinohe et al. 2010; Guo et al. 2015), activation of a RIPK1-RIPK3-Drp1 signalling pathway (Wang et al. 2014), TRAF3dependent ubiquitination and activation of ASC (Siu et al. 2019), RNA cleavage by RNase L

367 (Chakrabarti et al. 2015), and reactive oxygen species (ROS) production (Allen et al. 2009). 
Intestinally expressed NLRP6 has previously been shown to be required for innate antiviral response against enteric virus infection (Wang et al. 2015). Loss of NLRP6 in mice or cells leads to higher EMCV viral loads and diminished antiviral gene expression. NLRP6 restricts enteric virus infection by inducing the expression of type I/III IFNs and IFN-stimulated genes (ISGs).

374 Although NLRP6 alone is capable of binding with long dsRNA, it forms a viral RNA-sensing complex with DEAH-box helicase DHX15 to sense viral dsRNA and induce MAVS-dependent IFN response. NLRP6-mediated signalling is independent of RIG-I and MDA5. Activation of the NLRP6-DHX15 sensing complex by rotavirus and reovirus also results in inflammasome activation (Xing et al. 2021b). Thus, NLRP6 functions with DHX15 as a viral RNA sensor which not only constitutes the first line of antiviral defense in the intestinal epithelia, but also provokes intestinal inflammation.

\section{NLRP9b}

Another intestine-specific NLR, NLRP9b, has also been shown to restrict rotavirus infection via RNA helicase DHX9 (Zhu et al. 2017). Although NLRP9b itself does not bind RNA, it recognizes short dsRNA via DHX9 and triggers the formation of inflammasome complex, leading to IL-18 release and activation of pyroptosis through gasdermin D (GSDMD). Mice with conditional depletion of NLRP9b or other inflammasome components, caspase-1 and ASC, in the intestine are more susceptible to rotavirus infection and have higher viral loads, independent of the effects ascribed to microbiota. GSDMD-mediated pyroptosis is of particular importance to restrict rotavirus replication through induction of premature death of infected intestinal epithelial cells and maintenance of intestinal homeostasis. Hence, NLRP9b, together with DHX9, functions as an enteric viral RNA sensor in the host innate immune defense against rotavirus infection. 
NLRX1

NLRX1, the only member in the NLRX subfamily of NLRs, is unique for its mitochondrial localization through its $\mathrm{N}$-terminal mitochondrial targeting sequence (Moore et al. 2008; Tattoli et al. 2008; Hong et al. 2012). The C-terminal fragment of NLRX1 has been shown to specifically bind RNA with a stronger preference towards dsRNA and thus it is thought to be involved in the recognition of intracellular viral RNA in infected cells (Hong et al. 2012). NLRX1 indeed is an innate immune modulator with both positive and negative regulatory roles (Hong et al. 2012; Feng et al. 2017). Specifically, NLRX1 suppresses mitochondrial antiviral immunity by sequestering its interacting partner MAVS to interfere with RIG-I-MAVS-dependent signalling during viral infection (Moore et al. 2008; Allen et al. 2011). Sequestration of STING by NLRX1 has also been reported (Guo et al. 2016). In addition, NLRX1 forms a complex with mitochondrial protein TUFM to suppress IFN production but augment autophagy (Lei et al. 2012; Lei et al. 2013). Potentiation of innate antiviral response has also been noted in NLRX1deficient mice (Allen et al. 2011). These findings are in favour of a role for NLRX1 as a negative innate immune regulator. On the other hand, it has also been reported that MAVS signalling, IRF3 activation as well as IFN and cytokine production are not affected in the absence of 413 NLRX1 in cells upon Sendai virus infection or poly(I:C) stimulation (Rebsamen et al. 2011). 414 Additionally, NLRX1 is essential for IFN production and apoptosis in macrophages by 415 interacting with IAV protein PB1-F2 during infection (Jaworska et al. 2014). The mitochondrial 416 viral protein PB1-F2 has been shown to suppress MAVS signalling and NLRP3 inflammasome 417 activation, which might provide further support to the role of NLRX1 in interacting with and 
sequestering PB1-F2 to regulate innate immune responses in a positive manner (Cheung et al. 2020a; Cheung et al. 2020b; Cheung et al. 2020c). Finally, NLRX1 also enhances NF-KB signalling by inducing the production of ROS in response to diverse stimuli (Tattoli et al. 2008). These studies suggest a positive regulatory role for NLRX1 in innate immune responses. An explanation to the observed opposing regulatory effects of NLRX1 on innate immunity from a recent report suggests that NLRX1 could suppress MAVS-mediated IRF3 activation but at the same time facilitate virus-induced IRF1 expression (Feng et al. 2017), leading to differential regulation of different innate immune pathways. More work is required to clarify whether and how NLRX1 differentially modulate innate immune signalling in different contexts.

\section{OTHER RNA SENSORS}

In addition to RLRs and NLRs, several other proteins have emerged as RNA sensors. Below we will review several sensors that are thought to sense viral RNA directly. However, in some circumstances, some of them might also affect RNA sensing indirectly in a manner similar to the RNA-binding protein partners of RNA sensors that will be discussed in the next section. This is not uncommon. For example, LGP2 discussed above can be seen as either an RNA sensor or an RNA-binding partner of RIG-I and MDA5 sensors.

\section{DExD/H-box RNA helicases}

$\mathrm{DExD} / \mathrm{H}$ helicases are characterized by a series of amino acid motifs that form the RNA and ATP binding sites of the helicase core (Taschuk and Cherry 2020). To date, 42 DEAD-box helicases and 16 DEAH-box helicases have been identified in humans. Helicases are enzymes that catalyze the unwinding of duplex nucleic acids in an energy-dependent manner. They 
442 participate in nearly every cellular process involving RNA (Fullam and Schroder

443 2013). Emerging evidence suggests that cellular RNA helicases could function in the 444 recognition of foreign nucleic acids and impact viral replication. The ability of DExD/H-box 445 helicases to recognize RNA in a sequence-independent manner, together with its involvement 446 in diverse cellular functions, lead them to influence innate recognition and viral infection in 447 multiple ways. Indeed, in addition to the well-studied RLRs, various non-RLR DExD/H-box 448 helicases have also been implicated in RNA sensing in infected cells, with antiviral or pro-viral 449 roles. Non-RLR members of the family of $\mathrm{DExD} / \mathrm{H}$-box helicases with reported functions in 450 RNA sensing are listed and introduced briefly in the table below.

453 TABLE 1. DEXD/H-box helicases involved in RNA sensing

\begin{tabular}{ccc}
\hline $\begin{array}{c}\text { DEXD/H-box } \\
\text { helicases }\end{array}$ & Functions in RNA sensing & $\begin{array}{c}\text { Key } \\
\text { references }\end{array}$ \\
\hline $\begin{array}{c}\text { DDX1, } \\
\text { DDX21 } \\
\text { and } \\
\text { DHX36 }\end{array}$ & $\begin{array}{c}\text { Form a complex as a dsRNA sensor to trigger IFN } \\
\text { response via TRIF pathway }\end{array}$ & $\begin{array}{c}\text { (Zhang et al. } \\
\text { 2011a) }\end{array}$ \\
DDX3 & $\begin{array}{c}\text { Binds to viral RNA and interacts with MAVS to } \\
\text { mediate IFN induction during early viral infection }\end{array}$ & $\begin{array}{c}\text { (Oshiumi et } \\
\text { al. 2010b) }\end{array}$ \\
& $\begin{array}{c}\text { As a sensor of abortive HIV-1 RNA to induce MAVS- } \\
\text { mediated IFN response }\end{array}$ & $\begin{array}{c}\text { (Gringhuis et } \\
\text { al. 2017) }\end{array}$ \\
& $\begin{array}{c}\text { Interacts with NLRP3 to induce inflammasome } \\
\text { activation }\end{array}$ & $\begin{array}{c}\text { (Samir et al. } \\
\text { 2019) }\end{array}$ \\
& As a potent ISG suppressor working via the mRNA & (Lumb et al. \\
degradation machinery & 2017) \\
& As an RNA co-sensor for RIG-I to enhance antiviral \\
signalling & (Nunez et al. \\
& & $\begin{array}{c}\text { 2018; } \\
\text { Zhang et } \\
\text { al. 2021) }\end{array}$
\end{tabular}


DHX9

DHX15

DDX17

DDX19A

DDX23

DDX24

DHX29

DHX33

DHX36
As a viral dsRNA sensor and interacts with MAVS to mediate IFN response in myeloid dendritic cells

Binds dsRNA to mediate inflammasome activation by Nlrp9b

As a viral dsRNA sensor and interacted with MAVS to mediate IFN response in myeloid dendritic cells

As a viral RNA co-receptor for RIG-I to induce MAVSmediated IFN response

Interacts with NLRP6 to mediate IFN response and inflammasome activation

Binds to an essential stem-loop in bunyaviral RNA to restrict infection in an interferon-independent fashion

As a cytosolic viral RNA sensor for porcine reproductive and respiration syndrome virus to mediate NLRP3-dependent inflammasome activation

As a viral dsRNA sensor to induce TRIF- or MAVSdependent innate antiviral responses

Sequesters RNA agonists of RLR and hijacks adaptor proteins FADD and RIP1 to suppress viral RNAdependent IFN production

As an RNA co-sensor for MDA5 to mediate antiviral immunity against EMCV

As a cytosolic co-sensor for RIG-I to mediate nucleic acid-induced MAVS-dependent IFN response

As a cytosolic sensor of RNA such as cleavage product of RNase L to activate the NLRP3 inflammasome

As a dsRNA and viral RNA sensor independent of RIGI/MDA5 to induce IFN response in myeloid dendritic cells

As a regulator of PKR-dependent antiviral stress granule to facilitate viral RNA recognition by RIG-I

Forms an RNA-sensing complex with DDX1 and DDX21 to activate IFN response
(Zhang et al. 2011b)

(Zhu et al. 2017)

(Lu et al. 2014)

(Pattabhi et al. 2019)

(Xing et al. 2021b)

(Moy et al. 2014)

(Li et al. 2015)

(Ruan et al. 2019)

(Ma et al. 2013)

(Zhu et al.

2018)

(Sugimoto et al. 2014)

(Mitoma et

al. 2013;

Chakrabarti

et al. 2015)

(Liu et al. 2014)

(Yoo et al. 2014)

(Zhang et al. 2011a) 
DDX41 As a sensor for RNA/DNA hybrid generated from (Stavrou et retroviral reverse transcription to trigger an al. 2018) immune response

DDX60 Binds viral nucleic acids and promoted the binding of (Miyashita et RIG-I to dsRNA to facilitate RLR-mediated IFN al.2011) signalling

DDX60L As a direct effector to inhibit HCV replication and (Grunvogel et impacts viral RNA sensing through RIG-I- al. 2015) dependent IFN response

SNRNP200 As an RNA sensor and TBK1 adaptor for the activation of IRF3-mediated antiviral IFN response

(Tremblay et al. 2016)

ZBP1

457 Z-DNA binding protein 1 (ZBP1), also known as DAI or DLM-1, is IFN-inducible and has initially 458 been suggested as a cytosolic B-DNA sensor to trigger IFN response (Takaoka et al. 2007), but this finding has not been substantiated by later studies. In addition to the role of ZBP1 in the 460 activation of IFN response, several studies have implicated ZBP1 as an inducer of cell death upon viral infection (Kuriakose et al. 2016; Nogusa et al. 2016; Thapa et al. 2016; Maelfait et al. 2017). Programmed cell death, such as pyroptosis, apoptosis and necroptosis, serves as an important immune defense mechanism to clear infected cells and restrict viral replication (Maelfait et al. 2017). Upon sensing of Z-RNA by ZBP1, RIPK3 and caspase 8 are recruited, resulting in the activation of ZBP1-NLRP3 inflammasome, the assembly of which is facilitated by caspase 6 (Zheng et al. 2020). Parallel to this, another complex containing AIM2 and pyrin 467 is also formed to mediate inflammasome activation, pyroptosis and other forms of cell death 468 (Lee et al. 2021). Whether these two complexes are mutually exclusive and how they cooperate in the induction of inflammasome activation and cell death require further investigations. 
IAV is known to induce necroptosis and other forms of cell death driven by RIPK3 (Nogusa

473 et al. 2016). ZBP1 emerges as the link between viral infection and RIPK3-mediated cell death 474 (Kuriakose et al. 2016; Thapa et al. 2016; Maelfait et al. 2017). Particularly, ZBP1 has been 475 implicated as an innate immune sensor of IAV PAMPs. In one study, ZBP1 has been shown to sense IAV nucleoprotein NP and polymerase subunit PB1, leading to NLRP3 inflammasome activation and induction of cell death (Kuriakose et al. 2016). However, in another study, ZBP1 has been shown to bind IAV genomic RNA and then recruit RIPK3 to initiate the downstream death signalling (Thapa et al. 2016). The results on the lethality of ZBP1-deficient mice upon IAV infection from the two studies are also contradictory (Kuriakose et al. 2016; Thapa et al. 2016). In addition to IAV, ZBP1 has also been implicated in necroptosis induced upon infection of mouse cytomegalovirus (Maelfait et al. 2017). The binding of RNA by Z-binding domains of ZBP1 is required for the induction of necroptosis. However, one nuance of ZBP1-RIPK3 signalling has recently been demonstrated in Zika virus-infected neurons. The activated ZBP1RIPK3 signalling in these cells does not induce necroptosis, but induces IRG1 enzyme to synthesize itaconate (Daniels et al. 2019), which in turn inhibits viral replication, suppresses inflammasome activation and prevents cell death (Hooftman et al. 2020). Recent findings have revealed exciting new details of how ZBP1 functions in RNA sensing to impinge on IFN response, inflammasome activation and programmed cell death. However, further studies are warranted to resolve some discrepancies in the literature and to clarify several key issues concerning the ability of ZBP1 to activate both NLRP3 and AIM2 inflammasomes, the identity of IAV PAMP(s) sensed by ZBP1, the phenotypes of IAV-infected $Z b p 1^{\%}$ mice, and the mechanism by which inflammasome activation and cell death are induced or inhibited. 


\section{HMGBS}

497 The family of high-mobility group box proteins (HMGBs) is comprised of four members, namely HMGB1, HMGB2, HMGB3 and HMGB4 (Taniguchi et al. 2018). HMGB1, HMGB2 and HMGB3 proteins are highly conserved with over $80 \%$ identity in their amino acid sequences. These three proteins contain two DNA-binding HMG domains and an acidic tail while HMGB4 contains only two HMG domains but lacks the acidic tail. Except that HMGB1 has a ubiquitous expression, other HMGB proteins have a restricted expression in specific target tissues. It is thus postulated that HMGB1 may have broad roles in various tissues, while other HMGBs function redundantly in specific tissues. HMGBs are highly expressed in the nucleus but also exist in the cytosol as well as the extracellular fluids. They perform differential roles intracellularly and extracellularly. Inside the nucleus, HMGBs bind to DNA in a structuredependent and sequence-independent manner for chromatin remodelling. HMGBs in the extracellular compartment however function as alarmins, which are endogenous molecules released to activate the immune system upon tissue damage. Although HMGBs are highly conserved, they still exhibit differential binding specificity towards different nucleic acids. HMGB1 and HMGB3 bind both dsRNA and dsDNA while HMGB2 binds only dsDNA (Yanai et al. 2009). HMGBs have also been shown to bind all TLR agonistic nucleic acids. Loss of single or three HMGBs has been found to significantly dampen nucleic acid-stimulated as well as

514 virus-induced innate immune responses via IRF3 and NF-KB pathways. In all, HMGBs may 515 function as universal sentinels for nucleic acids and are required to activate nucleic-acid516 induced innate immune responses in full (Yanai et al. 2009). Particularly, HMGB1 interacts 517 with TLR9 and RLRs, suggesting that nucleic acid-bound HMGBs may function as co-sensor for 
various PRRs to facilitate their recognition of nucleic acid agonists, leading to the potentiation

519 of innate IFN response (Yanai et al. 2009).

520

$521 \quad$ IFITs

522 Interferon-induced proteins with tetratricopeptide repeats (IFITs) are a family of proteins 523 induced by interferon, viral infection or PAMP recognition [reviewed in (Diamond and Farzan 524 2013; Fensterl and Sen 2015)]. As their names suggest, IFITs harbour multiple 525 tetratricopeptide repeats, which are critical for protein-protein interactions. To date, four 526 members including IFIT1, IFIT2, IFIT3 and IFIT5 have been characterized in humans. They have 527 a cytoplasmic localization with no known enzymatic activity. IFITs have no basal expression 528 under unstimulated conditions in most cell types but are rapidly and strongly induced upon 529 viral infection. Subsets of IFIT genes are also induced selectively in different cell types, 530 suggesting a non-redundant antiviral function for different IFITs. IFITs are also induced in an 531 IFN-independent manner by transcription factors such as IRF1, IRF3, IRF5 and IRF7. IFITs are 532 known to exhibit antiviral activity against various families of viruses through diverse 533 mechanisms of action. Firstly, IFIT1 and IFIT2 inhibit translation initiation by binding to the 534 eukaryotic initiation factor 3 (Guo et al. 2000). Secondly, IFIT1 recognizes non-2'-O methylated viral RNA and inhibits viral translation possibly by competing with the pre536 initiation complex for viral RNA, or by serving as a scaffold for other proteins that regulate 537 translation (Daffis et al. 2010; Habjan et al. 2013). Thirdly, IFIT1 serves as a viral RNA sensor 538 to detect uncapped 5'-triphosphate RNA and sequester viral RNA (Pichlmair et al. 2011). 539 Finally, IFIT1 binds to viral proteins such as helicase E1 of human papillomavirus to inhibit viral 540 replication (Terenzi et al. 2008). IFIT3 binds to IFIT1 to stabilize the latter and enhance its 
541 binding to non-self RNA. In this regard, IFIT3 serves as a co-sensor of IFIT1 to achieve optimal 542 antiviral activity (Fleith et al. 2019).

545 Poly(ADP-ribose) polymerase 9 (PARP9) belongs to the PARP family, which is known to be 546 critical in DNA repair, cell death and survival, and chromatin remodelling. As an inactive 547 mono-ADP-ribosyltransferase in the PARP family, PARP9 is not well characterized and its 548 functions are largely unknown. A functional screen for activators of IFN response in the PARP 549 family reveals that PARP9 functions as a MAVS-independent RNA sensor. PARP9 binds to viral 550 dsRNA and recruits PI3K and AKT3 to phosphorylate and activate IRF3 and IRF7 (Xing et al. 551 2021a). It will be of great interest to see under what other conditions this PI3K-AKT3552 dependent non-canonical pathway for IFN production might also be activated.

SAFA

555 Scaffold attachment factor A (SAFA), also known as heterogeneous ribonucleoprotein $U$, is a 556 nuclear matrix protein that has initially been implicated as a nuclear viral dsRNA sensor for 557 both DNA and RNA viruses (Cao et al. 2019). It has been demonstrated that SAFA potentiates 558 antiviral immune response by activating both enhancers and super-enhancers of important antiviral effectors through chromatin remodelling. Very recently, SAFA has been shown to be 560 a novel cytoplasmic RNA sensor for severe fever with thrombocytopenia syndrome virus 561 (SFTSV) infection to trigger innate antiviral response (Liu et al. 2021a). Upon SFTSV infection, 562 SAFA remains in the cytoplasm through an interaction with SFTSV nucleocapsid protein. 563 Cytoplasmic SAFA then recognizes cytoplasmic SFTSV genomic RNA and promotes subsequent 564 activation of the STING-TBK1 signalling pathway. On the other hand, it has previously been 
shown that SFTSV infection induces BAK/BAX-dependent mitochondrial DNA (mtDNA) release

566 (Li et al. 2020b). Thus, it remains elusive whether activation of the STING pathway might be 567 caused by mtDNA release and/or SAFA-mediated RNA recognition. Further investigation is 568 required to clarify this.

\section{RNA-BINDING PROTEIN PARTNERS OF RNA SENSORS}

In this part, we will focus on RNA-binding proteins that are not RNA sensors per se but interact with RNA sensors to modulate their sensing activity (Figure 2). Because RNA sensors also bind to RNA, it is technically challenging to rule out the possibility that the interactions between RNA sensors and their RNA-binding protein partners are mediated by RNA. The functional outcome of these interactions is more important than RNA dependence. As described above, the interaction between RIG-I and RIPLET occurs only in the presence of RNA (Cadena et al. 2019). Likewise, TRIM65 interacts with MDA5 only when RNA induces oligomerization and filament formation of MDA5 (Kato et al. 2021). When we discuss the interactions between RNA sensors and their RNA-binding protein partners, several critical issues should be taken into full consideration. Firstly, it is of interest to see mechanistically how the RNA-binding protein partners modulate the sensing activity of the RNA sensors. Presumably, the partners might select or recruit certain types of RNA to the sensors. In addition, the partners could induce conformational change or alter the catalytic activity or activation threshold of the sensors. Secondly, many RNA-binding protein partners of RNA sensors are multifunctional and are critically involved in other processes of RNA recognition and processing (Heyam et al. 2015). How these different processes are coordinated and differentially regulated requires more analysis. Thirdly, different RNA-binding protein partners of RNA sensors might interact with each other to modulate the sensing activity jointly. They could be the components of the 
same multi-subunit protein complex for RNA sensing. Their actions might either be synergistic or antagonistic. Thus, these partners should not be studied in isolation.

591

592

PACT

PACT, also known as PRKRA, a dsRNA-binding protein harbouring three tandem repeats of dsRNA binding motifs, has initially been identified as a direct protein activator of PKR through their heterodimerization in response to diverse stress signals, leading to inhibition of protein translation (Patel and Sen 1998; Patel et al. 2000). Although PACT activation of PKR and its impact on proinflammatory response have been well documented (Chukwurah et al. 2021), more recent studies have also reported a negative regulatory role for PACT on PKR activation (Clerzius et al. 2013; Dickerman et al. 2015; Meyer et al. 2018). Phenotypic defects in PACTdeficient mice can be rescued by additional knockout of PKR or expression of a dominantnegative mutant of PKR, suggesting a primary function of PACT as a suppressor of aberrant PKR activation (Dickerman et al. 2015). Furthermore, the PKR-suppressive role of PACT has also been observed during HIV infection (Clerzius et al. 2013) and under the deficiency of the splicing factor TIA1/TIAL1 (Meyer et al. 2018). Additionally, PACT has also been implicated to mediate RNA interference and miRNA processing (Lee et al. 2006; Kok et al. 2007).

Soon after the discovery of PACT, its importance and involvement in innate antiviral response have already been documented in Newcastle disease virus infection (Iwamura et al. 2001). We have also shown that the interplay between PACT and IAV polymerase is critical to 610 the outcome of viral infection and antiviral response (Chan et al. 2018). One prominent role for PACT in innate antiviral response is to serve as a cellular activator of both RIG-I and MDA5

612 for induction of IFN signalling and potentiation of antiviral response (Kok et al. 2011; Ho et al. 
613 2016; Lui et al. 2017). Specifically, we have previously shown PACT to be a cellular activator

614 of RIG-I by physically binding to the C-terminal repression domain of RIG-I and potently 615 stimulating RIG-I-induced type I interferon production (Kok et al. 2011). Additionally, PACT

616 also functions as a coactivator of MDA5 by promoting MDA5 oligomerization subsequent to 617 dsRNA-induced activation (Lui et al. 2017).

Exactly how PACT activates RIG-I and MDA5 remains to be elucidated. As mentioned above, the role of PACT resembles that of LGP2, which lacks a CARD domain and is therefore considered incompetent for signal transduction. In this regard, PACT also binds LGP2 and this binding controls the inhibition of RIG-I and the activation of MDA5 by LGP2 (Sanchez David et al. 2019). One probable role of PACT is to concentrate RLR agonists for subsequent transfer to RLRs. This requires selective and high-affinity binding with RNA. Indeed, PACT interacts with measles virus defective-interfering RNA of the copy-back type, an agonist of RIG-I (Ho et al. 2016). This and other RNA agonists of PACT and RIG-I hold the promise to be further developed as antivirals and vaccine adjuvants. Notably, biochemical and structural analysis of the role of PACT and its homolog TRBP in Dicer function in miRNA biogenesis has revealed mechanistic details for guide strand selection. In particular, PACT enhances the guide strand selection of some miRNAs (Noland and Doudna 2013). Reconstitution experiments indicate that PACT inhibits pre-siRNA processing by Dicer. In addition, Dicer-TRBP and Dicer-PACT complexes produce different miRNA isoforms (Lee et al. 2013b). The importance of PACT and TRBP to Dicer function has been verified by the use of a catalytically active Dicer that cannot bind PACT or TRBP (Wilson et al. 2015). Together with TRBP, PACT plays an important role in selecting specific RNA substrates and ensuring fidelity and specificity of Dicer cleavage. 
MDA5, it could not be ruled out that the general principle might also apply in RLR-mediated RNA sensing. Further investigations similar to those performed on PACT and Dicer are required to clarify whether PACT might be a key determinant of substrate concentration and selection for RIG-I and MDA5. Nevertheless, the interaction between RIG-I and PACT represents a theme in which RNA-binding partners facilitate the function of RNA sensors.

TRBP is a homolog of PACT. Whereas PACT is an activator of PKR, TRBP exhibits an inhibitory effect on PKR (Park et al. 1994). However, both TRBP and PACT facilitate Dicermediated small RNA processing (Kok et al. 2007; Wilson et al. 2015). Whereas PACT and TRBP have apparently opposing functions on PKR, they cooperate to facilitate Dicer. Detailed analysis of the effects of PACT and TRBP on PKR and Dicer does indicate that the roles of PACT and TRBP are indeed distinct and complementary. Consistent with this, the inhibitory effect of TRBP on RIG-I activation has recently been documented (Vaughn et al. 2021). Interestingly, this inhibition is independent of PACT or PKR but requires TRBP's dsRNA binding ability. It will be of interest to determine whether TRBP might sequester RIG-I agonists and how TRBP could affect MDA5 activation.

2017). Interestingly, structural asymmetry has been observed in PACT and TRBP homodimers and it is ascribed to residue composition in the homodimer interface (Heyam et al. 2017). The same C-terminal dsRNA-binding domain in PACT or TRBP also mediates the interaction with Dicer. In the case of Dicer, a 1:1 complex of Dicer-PACT or Dicer-TRBP can be formed with Dicer interacting with either PACT or TRBP (Heyam et al. 2017). Although the co-existence of both PACT and TRBP in a multi-component macromolecular complex cannot be excluded, 
661 their direct interaction with Dicer is mutually exclusive (Heyam et al. 2017). Whether PACT 662 and TRBP interact with RIG-I and MDA5 in a similar manner remains to be determined. 663 Because the inhibitory effect of TRBP on RIG-I is PACT-independent (Vaughn et al. 2021), their 664 interaction with RIG-I might indeed be mutually exclusive.

\section{PKR}

667

PKR is a dsRNA-activated serine-threonine kinase that plays a major role in a number of different cellular processes such as mRNA translation, transcriptional control, regulation of apoptosis, and proliferation [reviewed in (Gal-Ben-Ari et al. 2018; Chukwurah et al. 2021)]. Particularly, PKR is well-known for its role as a key innate immune sensor. PKR harbours two tandem N-terminal dsRNA-binding motifs (dsRBMs) and a C-terminal kinase domain (Hull and Bevilacqua 2016). PKR, as its name suggested, was originally described as a dsRNA activated kinase but more recent studies have shown that ssRNA or RNA with 5'-triphosphate and limited secondary structure could also activate PKR [reviewed in (Hull and Bevilacqua 2016)]. In the presence of RNA agonists, PKR dimerizes via binding of RNA by its dsRBMs and then autophosphorylates to become activated. Phosphorylated active PKR will subsequently phosphorylate and suppress elF $2 \alpha$, thereby inhibiting translation initiation and causing apoptosis. In addition to its role as a PRR to trigger translation repression upon RNA recognition, PKR has also been shown to modulate innate IFN response at several different steps. Firstly, PKR contributes to MDA5-induced IFN response against certain RNA viruses via regulation of IFN transcript stability (Schulz et al. 2010). Secondly, PKR transduces the activation signal of MDA5 in the activation of IFN production through direct interaction with MDA5 (Pham et al. 2016). The catalytic activity of PKR is required for this function. Thirdly, in response to osmotic stress, PACT and PKR are activated to inhibit the interaction between NF- 
$\kappa B$ c-Rel and NFAT5, but promote the formation of an NF- $\mathrm{B}$ p $65-\mathrm{NFAT5}$ complex. As a result, NFAT5-dependent osmoprotective gene expression is suppressed and p65-dependent proinflammatory gene expression is enhanced (Farabaugh et al. 2020). Finally, PKR is the target of other innate immune regulators such as ADAR1, RNase L and Dicer (Nie et al. 2007; Manivannan et al. 2020; Montavon et al. 2021). Taken together, PKR is a dsRNA-binding protein kinase that interacts with MDA5 and exerts its regulatory effects at multiple steps of the RNA sensing pathway.

\section{ADAR1}

The ADAR proteins belong to a gene family comprising three members, namely ADAR1, ADAR2 and ADAR3 (Lamers et al. 2019; Quin et al. 2021). ADAR1 is critically involved in balancing immune activation and self-tolerance. ADAR mutations as one of the causes of Aicardi-Goutières syndrome, a severe human autoimmune disease, are suggestive of the important negative regulatory roles of ADAR proteins in innate immune response (Rice et al. 2012). While ADAR1 and ADAR2 possess adenosine deaminase activity to catalyze adenosineto-inosine (A-to-I) editing at millions of sites in humans (Lamers et al. 2019; Heraud-Farlow and Walkley 2020), ADAR3 is catalytically inactive (Chen et al. 2000). Notably, the primary role of RNA editing by IFN-inducible ADAR1 is to dampen innate immune activation by unedited endogenous RNA. Stable dsRNA structures are believed to form by unedited inverted paired sequences, such as Alu elements, which could trigger the activation of various dsRNA sensing pathways. ADAR1 has been implicated in modulating canonical RLR-MAVS, PKR as well as oligoadenylate synthetase (OAS)-RNase L pathways [reviewed in (Lamers et al. 2019)]. 
Loss of ADAR1 in mice is embryonic lethal which has been associated with excessive IFN expression (Hartner et al. 2009). Later, it has been found that further deletion of MDA5 or

710 MAVS could rescue lethality in ADAR1-deficient embryonic mice (Mannion et al. 2014;

711 Liddicoat et al. 2015). Although deletion of RIG-I did not rescue embryonic lethality in ADAR1-

712 deficient mice (Pestal et al. 2015), in vitro studies did show a negative role for ADAR1 on RIG-

713 I activation. These findings suggested that RLRs are stimulated by endogenous dsRNA in the 714 absence of ADAR1 and that ADAR1 is capable of blocking RLR signalling for IFN production, 715 particularly through the MDA5-MAVS axis. A-to-I editing by ADAR1 is believed to be a crucial 716 mechanism for dampening MDA5-MAVS signalling induced by endogenous RNA since the 717 enzymatic activity of ADAR1 was shown to be essential for survival (Liddicoat et al. 2015). As such, MDA5 induces Z-RNA formation in Alu repeats, thereby providing a site for ADAR1 to anchor. Consequent editing by ADAR1 destabilizes dsRNA, leading to the termination of MDA5 action (Herbert 2021). Adar knockout alleles in mice can be rescued by concomitant deletion of Mavs or Mda5 (Bajad et al. 2020). PKR, LGP2 and IFN response are also required for the lethality of Adar mutant mice (Maurano et al. 2021). Although contradictory results have been reported showing RNA binding rather than editing activity of ADAR1 being responsible for suppressing RIG-I activation (Yang et al. 2014), this might be explained by differences in cell type-dependent activity of ADAR1. All in all, current findings indicate that A-to-I editing of endogenous RNA by ADAR1 is a critical element to prevent over-stimulation of RLRs and to maintain cellular homeostasis in RLR signalling. This has important implications in innate antiviral response. 
732 Upon activation, autophosphorylation of PKR takes place leading to subsequent 733 phosphorylation of elF $2 \alpha$ to shut down mRNA translation as a defense mechanism against 734 viral infection (Dar et al. 2005; Dey et al. 2005). By blocking the activation of PKR, an important 735 antiviral PRR, through both editing-dependent and -independent mechanisms, ADAR1 served 736 as a pro-viral host factor to promote replication of viruses including measles virus, vesicular stomatitis virus (VSV), and human immunodeficiency virus (HIV). In the case of an editingindependent mechanism, ADAR1 might bind directly with PKR to interfere with its dimerization and autophosphorylation, leading to the inhibition of elF $2 \alpha$ phosphorylation and stress granule formation. Restriction on viral mRNAs translation is then removed.

Lastly, ADAR1 also blocks the OAS-RNase L pathway. Upon dsRNA recognition, OAS proteins including OAS1, OAS2 and OAS3 produce 2',5'-oligoadenylates (2-5A $)$ (Lamers et al. 2019). This second messenger then binds to RNase $L$ to trigger its dimerization to give the enzymatically active form. RNase $L$ can cleave both viral and host RNA, leading to translation arrest, autophagy and apoptosis. RNase L deletion in cultured cells rescues the lethal phenotype of ADAR1-deficient cells. Additionally, IFN-induced 2-5 $A_{n}$ accumulation is higher in RNase L/ADAR1 double knockout cells than in wild-type and RNase L-knockout cells. These findings suggest that ADAR1 prevents the activation of OAS.

In summary, ADAR1 is an RNA editing enzyme that binds to and modifies RLR ligands. It 
756

757

\section{G3BP1}

Ras-GTPase-activating SH3 domain-binding protein 1 (G3BP1) is a crucial component of the mammalian cell stress granules (SG) which help minimize stress-related damage and promote cell survival (Mahboubi and Stochaj 2017). Viral infection has also been associated with SG assembly which attenuates viral replication (Onomoto et al. 2012; Cobos Jimenez et al. 2015). G3BP1 is a multidomain protein highly conserved among species. It carries a nuclear translocation factor-2-like domain, an acidic region, an RNA recognition motif (RRM), and a C-terminal glycine-rich RGG motif (Kim et al. 2019). G3BP1 influences viral RNA-induced IFN response as predicted by an integrative computational biology study (van der Lee et al. 2015). More recently, a report by Kim and colleagues has demonstrated G3BP1 as a critical positive regulator of the RIG-I-mediated IFN pathway (Kim et al. 2019). G3BP1 co-localizes with RIG-I and VSV. G3BP1 binds to both RIG-I and viral dsRNA via its RGG domain. Their computational modelling further reveals a juxtaposed interaction between G3BP1 RGG and RIG-I RNAbinding domains. Collectively, the studies suggest that G3BP1 might act as a co-sensor of RIGI to facilitate the sensing of viral RNA.

\section{KHSRP}

K-homology splicing regulatory protein (KHSRP) is an adenine and uridine-rich element (ARE)binding protein, serving as an important negative regulator of cytokine expression posttranscriptionally via various mechanisms including translational silencing, RNA instability, microRNA maturation, and transcriptional repression [reviewed in (King and Chen 2014)]. Indeed, most mRNAs encoding type I IFNs contain AREs in their 3' UTRs, subjecting them to mRNA decay or translational control through an ARE-dependent mechanism (King and Chen 
779 2014). A new function for KHSRP in innate antiviral response has been identified in two global

780 RNAi screens (Soonthornvacharin et al. 2017). KHSRP serves as a negative regulator of the 781 RIG-I pathway. It interacts with the C-terminal repressor domain (CTD) of RIG-I to maintain 782 RIG-I in the inactive state, thereby attenuating the sensing of viral RNA. Loss of KHSRP 783 increases RIG-I-mediated antiviral signalling and reduces viral replication both in vitro and in 784 vivo. Furthermore, KHSRP inhibits the binding of viral RNA to RIG-I plausibly through competition for binding to the RIG-I CTD, leading to suppression of RIG-I-mediated IFN response.

\section{MEX3C}

Mex-3 RNA binding family member C (MEX3C) belongs to a family of four RNA-binding proteins, named MEX3A, MEX3B, MEX3C and MEX3D, which have been implicated in RNA metabolism (Buchet-Poyau et al. 2007; Pereira et al. 2013). MEX3C is an E3 ubiquitin ligase with a role in regulating RIG-I-mediated IFN response (Kuniyoshi et al. 2014). MEX3C colocalizes with RIG-I in the stress granules in virus-infected cells. MEX3C could mediate K63linked ubiquitination of RIG-I and induce IFN production. Loss of MEX3C in mice dampens RIGI-dependent IFN production upon viral infection. Thus, MEX3C plays a critical role in the induction of RIG-I-mediated innate antiviral response.

\section{OAS-RNase L}

OAS family of IFN-inducible enzymes are activated in response to dsRNA to synthesize 2'-5' 800 phosphodiester-linked oligoadenylates (2-5An) from ATP (Hovanessian and Justesen 2007; 801 Kristiansen et al. 2011; Hur 2019). The $2-5 A_{n}$ serves as a second messenger and binds to the inactive monomeric RNase $L$ to induce its homodimerization or oligomerization for activation 
803 (Han et al. 2014; Hur 2019). Activation of RNase L then leads to the cleavage of cellular and 804 viral RNAs, resulting in cell death, inflammasome activation and inhibition of protein synthesis, 805 cell growth and viral replication (Hovanessian and Justesen 2007; Kristiansen et al. 2011; 806 Chakrabarti et al. 2015; Hur 2019). OAS-RNase L pathway represents an important innate 807 antiviral response for counteracting viral infection. OAS family comprises 4 members 808 including OAS1, OAS2, OAS3 and OASL, with OASL being the only enzymatically inactive 809 member (Hur 2019). Structurally, OAS1, OAS2 and OAS3 contain one, two, and three tandem 810 repeats, respectively, of nucleotidyl transferase (NTase) domain, which serves as template811 independent nucleotide polymerase. Upon dsRNA binding, OAS NTases will undergo a 812 conformational change to activate its enzymatic activity for $2-5 A_{n}$ production and 813 subsequently trigger downstream RNase L pathway. On the other hand, OASL, though 814 enzymatically inactive, also exhibits broad antiviral activity (Schoggins et al. 2011; Hur 2019). 815 OASL harbours two tandem repeats of ubiquitin-like domains and a pseudo-NTase domain for 816 RNA binding. These domains are essential for the antiviral activity of OASL. A study has 817 demonstrated that OASL interacts and co-localizes with RIG-I, and specifically mediates RIG-I 818 activation by mimicking polyubiquitin through its C-terminal ubiquitin-like domain (Zhu et al. 819 2014).

As mentioned above, RNase $L$ not only functions as a terminal executioner in IFN 822 signalling to mediate RNA cleavage and cell death (Boehmer et al. 2021), but also serves as a node for interaction with upstream regulators such as PKR to modulate IFN production either 824 positively or negatively, depending on the cell type (Banerjee et al. 2014; Manivannan et al. 825 2020). 


\section{TRIM proteins}

830 Tripartite motif (TRIM) proteins constitute the largest family of RING domain-containing E3

831 ubiquitin ligase involved in diverse cellular processes such as differentiation, autophagy, apoptosis, DNA repair and tumour suppression (Hatakeyama 2017). There are more than 80 TRIM family members in humans which typically share a conserved RING-B-box-coiled-coil domain organization (van Gent et al. 2018). Many studies have implicated TRIM proteins in the innate immune response against viral infection via various mechanisms [reviewed in (van Gent et al. 2018)]. Below, we will focus on the roles of RNA-binding TRIM proteins in RNA sensing. RNA-binding roles of TRIM proteins have been postulated to regulate their fate or ubiquitination efficiency (Williams et al. 2019).

841 TRIM21 is a ubiquitous E3 ubiquitin ligase serving as a cytosolic antibody receptor (Mallery et al. 2010). TRIM21 detects antibody-bound virions that enter the cytosol after cellular receptor attachment, endocytosis, and endosomal escape, thereby providing early protection to cells from potential productive infectious events and preventing fatal viral infection (Vaysburd et al. 2013). Antibodies are normally excluded from the cytosol and their presence in the cytosol is sensed by TRIM21 to activate innate immune pathways involving NF-KB, AP-1 and IRF3/5/7 847 (McEwan et al. 2013). RNA binding by TRIM21 has been postulated from the finding that replacing the proposed RNA-binding peptide in the TRIM25 PRY/SPRY domain with 849 homologous sequence from TRIM21 does not affect the RNA binding in the chimeric protein 850 (Choudhury et al. 2017; Williams et al. 2019). Whether RNA-binding property is a universal 
conserved feature of PRY/SPRY domains is still under debate. In one study, TRIM21 has been

852 implicated in the potentiation of nucleic acid sensing by cytosolic sensors cGAS or RIG-I

853 (Watkinson et al. 2015). It has been suggested that TRIM21 mediates the rapid degradation

854 of incoming viral capsids in the cytosol, thereby promoting early detection of viral genomes

855 by CGAS and RIG-I. TRIM21 has also been shown to promote innate antiviral response through 856 K27-linked polyubiquitination of MAVS (Xue et al. 2018). Without TRIM21, no significant 857 induction of immune response in the first 8 hours occurs upon infection by both DNA and RNA 858 viruses such as adenovirus and rhinovirus, whereas transfection of viral genomes triggers a 859 robust immune response in the same timeframe. Thus, TRIM21 facilitates early immune 860 response upon infection which ensures the best protection of the host against infection.

TRIM25

863 TRIM25 is a multi-domain, RING-finger E3 ubiquitin ligase with various crucial roles in RNAdependent pathways. It has been reported to bind RNA, which modulates its ubiquitination activity, subcellular localization and antiviral activity (Sanchez et al. 2018). TRIM25 is especially well-known for its vital role in RIG-I activation. TRIM25 has been shown to bind RIGI and subsequently mediate K63-linked ubiquitination to the N-terminal CARDs of RIG-I to enhance RIG-I signalling activity (Gack et al. 2007). However, the relevance of TRIM25 to RIGI activation has been challenged (Cadena et al. 2019; Hayman et al. 2019). Studies by several 870 different groups have suggested RIPLET, instead of TRIM25, as the requisite E3 ubiquitin ligase 871 for RIG-I activation (Oshiumi et al. 2009; Kato et al. 2021). Furthermore, TRIM25 has been 872 reported to regulate RIG-I negatively by stabilizing the ubiquitin-like protein FAT10, which 873 binds and sequesters RIG-I from signalling (Nguyen et al. 2016). A negative regulatory role of 874 TRIM25 has also been shown in K48-linked polyubiquitination and proteasomal degradation 
875 of MAVS (Castanier et al 2012). These findings might suggest a dual role for TRIM25 in 876 regulating RIG-I-mediated IFN production and antiviral response (Gack et al. 2007; Martin877 Vicente et al. 2017). Whether and how TRIM25 indeed mediates its effect on innate immune 878 signalling through RIG-I or alternative mechanisms requires further elucidation. In addition to 879 its roles in RIG-I regulation, TRIM25 has been shown as an E3 ubiquitin ligase for ISG15 (Zou 880 and Zhang 2006) as well as a cofactor of another cytosolic RNA sensor ZAP to inhibit viral replication (Li et al. 2017; Zheng et al. 2017). Interestingly, RIG-I activates TRIM25-dependent ISG15 conjugation by stabilizing TRIM25 mRNA (Wu et al. 2020). On the other hand, whereas ISG15 conjugation of RIG-I serves a negative regulatory role (Kim et al. 2008), ISG15 conjugation activates MDA5 (Liu et al. 2021b). These findings reflect the diverse roles of TRIM25 in innate immunity. Further investigations are required to clarify whether and how TRIM25 might mediate ISG15 conjugation but not K63-linked ubiquitination of RIG-I. In addition, it will be of interest to see whether RIG-I could induce a feedback regulatory loop through ISG15 conjugation to inhibit RIG-I but activate MDA5 concurrently.

TRIM44 is localized in the cytoplasmic compartment contributing to diverse pathological conditions like tumours, growth disorders, and neurodegeneration (Xiao et al. 2020). TRIM44 is an atypical TRIM family protein that lacks the RING-finger domain but harbours a zinc-finger domain that is often found in ubiquitin-specific proteases (USPs). The zinc-finger domain of TRIM44 functions as USP and thus TRIM44 is known as "USP-like-TRIM" (Urano et al. 2009). TRIM44 has also been reported to play important regulatory roles in the innate immune response. TRIM44 is induced in response to Sendai virus infection, which stabilizes MAVS by 
suppressing its K48-linked ubiquitination and subsequent degradation (Yang et al. 2013). Thus, TRIM44 serves as a positive regulator of the RIG-I pathway to enhance IFN production and promote antiviral response against viral infection.

902

TRIM56

TRIM56 is an IFN- and virus-inducible E3 ubiquitin ligase previously shown to restrict viral replication (Wang et al. 2011; Kane et al. 2016; Liu et al. 2016). It has been shown that the E3 ubiquitin ligase activity, the C-terminal structural integrity and the RNA-binding property of TRIM56 are essential for its antiviral activity against bovine viral diarrhoea virus and Zika virus, both of which are positive-sense single-stranded RNA viruses (Wang et al. 2011; Yang et al. 2019). On the contrary, another study has reported that a 63-residue C-terminal tail of TRIM56 is sufficient to curtail the replication of influenza A and B viruses, negative-sense single-stranded RNA viruses (Liu et al. 2016). On the other hand, it has also been reported that TRIM56 associates with innate immune signalling adaptor STING and promotes its ubiquitination, thereby enhancing cytosolic dsDNA-induced IFN response (Tsuchida et al. 2010). TRIM56-mediated ubiquitination of STING is further accentuated by UBXN3B (Yang et al. 2018). TRIM56 also mediates monoubiquitination and consequent activation of cGAS (Seo et al. 2018). These findings indicate the involvement of TRIM56 in both RNA and DNA sensing pathways. Mechanistically, it has been shown that TRIM56 acts as a positive regulator of TLR3 signalling (Shen et al. 2012). Extracellular dsRNA-induced expression of IFNs and ISGs is significantly enhanced by TRIM56 overexpression, whereas activation of IRF3 and production 920 of IFNs/ISGs are substantially blunted by TRIM56 depletion. Particularly, the importance of 921 TRIM56 on the establishment of antiviral state by TLR3 and TLR3-mediated cytokine 922 production has been noted during hepatitis C virus infection. Independent of the E3 ubiquitin 
ligase activity of TRIM56, it mediates its effect on the TLR3 pathway through the interaction with TRIF, an adaptor protein for TLR3 signalling against viral infection.

925

TRIM65

TRIM65 has been implicated in microRNA regulation and innate immunity (Li et al. 2014; Lang et al. 2017; Williams et al. 2019). Particularly, TRIM65 is involved in MDA5-mediated RNA sensing and IFN response (Lang et al. 2017). TRIM65 interacts specifically with RNA-bound oligomeric MDA5 to promote K63-linked ubiquitination, and subsequent activation of MDA5 (Kato et al. 2021). Depletion of TRIM65 does not affect RIG-I, TLR3 or cGAS signalling, whereas TRIM65 deficiency abolishes MDA5-mediated immune response including EMCV-induced IRF3 activation and IFN production. Eminently, Trim65-null mice are more susceptible to EMCV infection than wild-type animals and fail to produce type I IFN in vivo. Together, these findings indicated that TRIM65 is an essential component for MDA5 signalling and that TRIM65-mediated ubiquitination is crucial for MDA5 oligomerization and filament assembly.

\section{Zinc-finger proteins}

Zinc fingers are compact protein domains harbouring zinc ions for domain stabilization (Krishna et al. 2003). Zinc fingers are structurally diverse and exist in various zinc-finger proteins for different biological processes, such as replication and repair, transcription and translation, metabolism and signalling, cell proliferation and apoptosis (Krishna et al. 2003). Zinc fingers typically function as interaction modules for binding nucleic acids, proteins and small molecules (Krishna et al. 2003). Zinc-finger proteins are frequently regarded as DNAbinding proteins, but various classes of zinc-finger proteins have also been found to bind RNA and are involved in RNA metabolism (Fu and Blackshear 2017). Zinc-finger proteins are 
classified into 8 fold groups according to their structural homology (Krishna et al. 2003).

Below, we will discuss a few RNA-binding zinc-finger proteins with a role in RNA sensing and 949 innate immunity.

950

MCPIP1

Monocyte chemoattractant protein 1-induced protein 1 (MCPIP1), also known as ZC3H12A for zinc finger $\mathrm{CCCH}$-type containing $12 \mathrm{~A}$, is a $\mathrm{CCCH}$-type zinc-finger protein belonging to the 954 MCPIP family, which has originally been identified as a gene induced by MCP-1 (Zhou et al. 2006). With RNase activity, MCPIP1 has subsequently been shown to degrade mRNA of various pro-inflammatory cytokines and is thus implicated as a negative regulator of the cellular inflammatory responses (Matsushita et al. 2009; Lin et al. 2013; Sun et al. 2018). MCPIP1 contains a CCCH-type zinc-finger domain with RNA-binding potential at the middle region and a NYN domain with RNase activity at the N-terminus (Lin et al. 2013). An earlier study has implicated MCPIP1 as a broad-spectrum antiviral factor against diverse DNA and RNA viruses (Lin et al. 2013). The activities of RNase, RNA binding and oligomerization of MCPIP1 are essential for its antiviral function. It has been proposed that MCPIP1 binds to and degrades viral RNA directly, resulting in the inhibition of viral replication. Another study has also implicated MCPIP1 as a host antiviral factor, which binds and degrades viral RNA during HBV infection (Li et al. 2020a). However, the impact of MCPIP1 on type I IFN response has not been investigated. Later, three independent studies about the effect of MCPIP1 on IFN response have appeared but with contradictory findings (Chen et al. 2018; Qian et al. 2018; Sun et al. 2018). One work suggests MCPIP1 as a positive regulator of IFN response, 969 independent of its RNase or deubiquitinase activity (Qian et al. 2018). MCPIP1 potently promotes type I IFN signalling by enhancing ISRE promoter activity and ISG expression. On the 
971 other hand, the other two studies suggest a negative regulatory role for MCPIP1 in IFN

972 production, thereby serving a pro-viral function (Chen et al. 2018; Sun et al. 2018). MCPIP1

973 are thought to interact with several important effectors of IFN signalling including MAVS,

974 TRAF3, TBK1 and IKKE while at the same time MCPIP1 perturbs the formation of TRAF3-TBK1-

975 IKKE complex, thereby negatively regulating the activation of IRF3. Alternatively, MCPIP1 also

976 attenuates IFN response by degrading RIG-I mRNA upon IAV infection (Sun et al. 2018).

977 Whether MCPIP1 indeed serves as a positive or negative regulator of IFN response with 978 antiviral or pro-viral roles warrants further investigations.

981 Zinc-finger antiviral protein (ZAP), also known as ZC3HAV1 or ZC3H2, is an interferon982 inducible host antiviral factor that has been implicated in inhibiting replication of different 983 viruses including HIV-1, SARS-CoV-2, Sindbis virus, Ebola virus, hepatitis B virus, and murine 984 leukemia virus (Gao et al. 2002; Bick et al. 2003; MacDonald et al. 2007; Muller et al. 2007; 985 Zhu et al. 2011; Mao et al. 2013; Nchioua et al. 2020). Additionally, ZAP is also known to 986 regulate cellular gene expression post-transcriptionally through binding to specific host mRNA or host factor for RNA processing (Zheng et al. 2017). TRIM25, an E3 ubiquitin ligase mentioned above, has been implicated in modulating the antiviral activity of ZAP (Li et al. 2017; Zheng et al. 2017). Loss of TRIM25 abolishes antiviral activity of ZAP, which relates to 990 the importance of TRIM25-mediated ubiquitination for optimal ZAP binding to target RNA 991 (Zheng et al. 2017). The RNA-binding property of ZAP is crucial to its functions and it comes 992 from the four CCCH-type zinc-finger domains at the N-terminus of ZAP (Zheng et al. 2017). 993 The binding of RNA by ZAP is sequence-independent but structure-dependent (Chen et al. 994 2012; Zheng et al. 2017). The antiviral activity of ZAP depends on its binding to viral mRNAs 
995 (Lee et al. 2013a). Mechanistically, ZAP contains a CpG dinucleotide-binding pocket and it 996 binds to selected CpGs in viral RNAs as well as some cellular mRNAs (Meagher et al. 2019), 997 such as those encoding IFN-repressed genes (Shaw et al. 2021), to target them to degradation 998 by nucleases such as KHNYN (Ficarelli et al. 2019; Ficarelli et al. 2021). Particularly, during 999 murine leukemia virus (MLV) infection, ZAP serves as a cytosolic RNA sensor, independent of 1000 TLR and RLR pathways, to repress translation and promote degradation of viral transcripts 1001 (Lee et al. 2013a). ZAP also exhibits antiviral activity against HIV-1 and SARS-CoV-2, plausibly 1002 mediated at least in part through CpG nucleotides (Ficarelli et al. 2020; Nchioua et al. 2020). Recoding the viral genome by increasing the occurrence of $\mathrm{CpG}$ without changing the proteincoding capacity provides a new strategy to construct live attenuated strains of RNA viruses that are particularly susceptible to ZAP-dependent degradation (Odon et al., 2019).

\section{ZCCHC3} al. 2020). It not only influences cytosolic dsRNA sensing by RLRs (Lian et al. 2018b), but also plays a crucial role in cytosolic dsDNA sensing by cGAS (Lian et al. 2018a). Cytosolic RNA is primarily sensed by RLRs including RIG-I and MDA5. ZCCHC3 binds to dsRNA and enhances the binding of RIG-I and MDA5 to dsRNA, thereby potentiating the activation of RIG-I- and 1014 MDA5-mediated IFN response (Lian et al. 2018b). ZCCHC3 also recruits TRIM25 to RIG-I and MDA5 to facilitate their K63-linked ubiquitination and activation. However, as discussed 1016 above, whether TRIM25 mediates K63-linked ubiquitination of RIG-I and MDA5 remains 1017 controversial (Oshiumi et al. 2009; Kato et al. 2021). It would therefore be of interest to see 
ZCCHC3 depletion significantly dampens the expression of IFN and cytokines in cells, ZCCHC3deficient mice are also more susceptible to RNA virus infection. These findings support the notion that ZCCHC3 functions not only as a co-sensor of RIG-I and MDA5 but also as a positive regulator of RLR signalling. Likewise, ZCCHC3 is also critical to TLR3-mediated innate immune response in endosomes (Zang et al. 2020). ZCCHC3 serves as a positive regulator for TLR3mediated signalling. It facilitates the recruitment of adaptor protein TRIF to TLR3 upon stimulation, thereby enhancing TRIF oligomerization for TLR3-mediated signalling. Collectively, ZCCHC3 might contribute to multiple aspects of the innate immune response.

\section{ZFYVE1}

Zinc finger FYVE-type containing 1 (ZFYVE1) is a guanylate-binding protein with distinct roles in the innate immune response. It has been demonstrated as a positive regulator of TLR3mediated signalling (Zhong et al. 2020a) and a negative regulator of MDA5-mediated signalling (Zhong et al. 2020b). ZFYVE1 interacts with poly(I:C) and TLR3 through its FYVE domain (Zhong et al. 2020a). Thus, ZFYVE1 enhances TLR3 signalling by promoting ligand binding to TLR3 (Zhong et al. 2020a). The reduced expression of antiviral genes and susceptibility to inflammatory death induced by poly(I:C) in ZFYVE1-deficient mice also support the positive regulatory role of ZFYVE1 in TLR3-mediated innate immune response (Zhong et al. 2020a). Subsequently, the same group reported a negative regulatory role for ZFYVE1 in MDA5-mediated signalling (Zhong et al. 2020b). As discussed above, its effect is specific to MDA5 and it does not affect RIG-I-mediated signalling. While the loss of ZFYVE1 in cells enhances the expression of MDA5-mediated antiviral genes, loss of ZFYVE1 in animals also protected them from lethality induced by EMCV that is sensed by MDA5 (Zhong et al. 2020b). Interaction of ZFYVE1 with MDA5 and viral RNA has been noted (Zhong et al. 2020b). 
ZFYVE1 competes with MDA5 for viral RNA binding and thus dampens the activation of MDA5

1044 (Zhong et al. 2020b). The distinct roles of ZFYVE1 on TLR3 and MDA5 might appear at odds 1045 but this also illustrates the complexity and the tight control of the innate immune system.

1046

1047 ZNF598

1048 Zinc finger protein 598 (ZNF598) is a ubiquitously expressed E3 ubiquitin ligase with an N1049 terminal RING-finger domain as well as four N-terminal and one C-terminal C2H2-type zinc1050 finger domains (Garzia et al. 2017). ZNF598 is an RNA-binding protein that binds to the 1051 translating mRNA and tRNAs on ribosomes and has been implicated in ribosome-associated 1052 quality control (Garzia et al. 2017). ZNF598 is also known as a negative regulator of RIG-I to 1053 prevent excessive innate immune response during viral infection (Wang et al. 2019a). ZNF598 1054 interacts with RIG-I and attenuates RIG-I-mediated IFN response. Depletion of ZNF598 1055 potentiates IFN expression in IAV-infected cells, which is mainly mediated through the RIG-I 1056 pathway. Mechanistically, ZNF598 promotes non-covalent binding of ubiquitin-like modifier 1057 FAT10 to RIG-I, so that RIPLET-mediated K63-linked ubiquitination of RIG-I is hindered (Wang 1058 et al. 2019a). RIG-I activation is known to require RIPLET-mediated K63-linked ubiquitination

1059 (Oshiumi et al. 2009; Oshiumi et al. 2010a; Oshiumi et al. 2013; Cadena et al. 2019; Hayman 1060 et al. 2019). As a result, RIG-I activation and thus RIG-I-mediated innate immune response are 1061 both attenuated in the presence of ZNF598. This represents an important mechanism to 1062 prevent an excessive immune response.

1065 Zinc finger NFX1-type containing 1 protein (ZNFX1) is an IFN-induced, mitochondrial-localized 1066 helicase belonging to the helicase superfamily 1 (Wang et al. 2019c). ZNFX1 acts as a dsRNA 
sensor to specifically counteract RNA viruses such as VSV, EMCV and IAV (Wang et al. 2019c).

1068

1069

1070

1071

1072

1073

1074

1075

1076

1077

1078

1079

1080

1081

1082

1083

1084

1085

1086

1087

1088

1089

1090

ZNFX1 binds to viral RNA directly and then specifically interacts with MAVS, but not TRIF, MyD88 or STING, to elicit type I IFN response upon virus infection. Loss of ZNFX1 in cells and mice enhances viral replication and dampens IFN production. The ability for ZNFX1 in eliciting

IFN response has also been shown to be RIG-I- and MDA5-independent. ZNFX1 deficiency in humans predisposes to severe viral or bacterial infections, monocytosis and multisystem inflammation (Le Voyer et al. 2021; Vavassori et al. 2021). All these findings suggest that ZNFX1 plays a crucial role as a novel RNA sensor in the antiviral immune response against RNA viruses.

\section{VIRAL PERTURBATION OF RNA-BINDING PARTNERS OF RNA SENSORS}

Viral countermeasures to evade host RNA sensing have been well described (Beachboard and Horner 2016; Chatterjee et al. 2016). Since existing reviews primarily focus on the viral perturbation of RNA sensors (Chan and Gack 2016; Fung et al. 2020), we will provide a nonexhausted discussion on how viruses subvert the function of RNA-binding partners of RNA sensors. The viral counter-defense not only provides a glimpse of the complexity of virus-host interaction, but also highlights the importance of the RNA-binding partners in RNA sensing.

With crucial roles in RLR-mediated IFN response, PACT is a key host factor frequently targeted by viruses for IFN antagonism. Diverse classes of viruses have developed measures to antagonize PACT-mediated IFN response for their successful survival and replication. In many cases, the viruses encode a viral dsRNA-binding protein to perturb the function of PACT. Herpes simplex virus 1 Us11 protein is the first example for this viral strategy (Kew et al. 2013). The study also reminds us of the importance of viral RNA sensing even during the course of 
1091

1092

1093

1094

1095

1096

1097

1098

1099

1100

1101

1102

1103

1104

1105

1106

1107

1108

1109

1110

1111

1112

1113

1114

DNA virus infection. MERS-COV ORF4a protein provides another example in which a viral dsRNA-binding protein counteracts PACT activation of RIG-I and MDA5 (Siu et al. 2014). In the case of Ebola virus VP35 protein, mutual antagonism between PACT and VP35 has been shown (Luthra et al. 2013). Whereas VP35 suppresses the IFN-inducing property of PACT, PACT also suppresses the activity of VP35 in viral RNA replication. The infection outcome is therefore affected by this pair of interacting partners. Generally consistent with this trend, mutual antagonism between IAV polymerase and PACT has also been reported (Chan et al. 2018). In addition, various other viral proteins including arenavirus nucleoprotein (Shao et al. 2018), IAV NS1 (Tawaratsumida et al. 2014), as well as mouse hepatitis virus and SARS-CoV nucleocapsid (Ding et al. 2017) have also been shown to suppress PACT-induced RLRdependent IFN production through specific interaction with PACT.

Interestingly, it is not uncommon for viruses to use one single IFN-antagonizing protein to target several different RNA sensors and their RNA-binding protein partners. For example, IAV NS1 and Ebola virus VP35 are also known to antagonize the function of PKR, RIG-I, MDA5, OAS- RNase L and ZAP (Krug 2015; Tang et al. 2017; Banerjee and Mitra 2020). Likewise, vaccinia virus E3L also targets PKR, RIG-I, MDA5, OAS-RNase L, ZBP1 and ADAR1 (Marq et al. 2009; Perdiguero and Esteban 2009). On the other hand, some viruses employ more than one IFN antagonists to target the same RNA sensor or RNA-binding partner. In particular, both IAV and SARS-CoV-2 use multiple viral proteins to target PACT and RIG-I (Wong et al. 2016; Malik and Zhou 2020). Recombinant viruses defective of one or more of the viral antagonists of PACT and RIG-I are severely attenuated. For example, NS1-deficient IAV has been used as a live attenuated vaccine in animals (Richt and García-Sastre 2009) and is a promising platform for development of live attenuated vaccines in humans (Wang et al. 2019b). 
1116 Viral subversion of PKR and ADAR1 has been reviewed elsewhere (George et al. 2009).

1117 Additional examples in which RNA-binding partners of RNA sensors are targeted by multiple 1118 viral proteins or viral RNA have been noted. The activity of G3BP1 in RNA sensing is known to 1119 be suppressed by foot-and-mouth disease virus 3A and leader proteins (Visser et al. 2019; 1120 Yang et al. 2020). Notably, a dengue virus non-coding RNA known as subgenomic flaviviral 1121 RNA also binds to G3BP1 and inhibits its activity (Bidet et al. 2014). In the case of ZAP, porcine 1122 reproductive and respiratory syndrome virus Nsp9 (Zhao et al. 2019) and Nsp4 (Zhao et al. 1123 2020), herpes simplex virus 1 UL41 (Su et al. 2015), as well as enterovirus A71 3C protease 1124 (Xie et al. 2018a) bind to and counteract the antiviral activity of ZAP.

\section{CONCLUDING REMARKS}

1127 Understanding of the mechanisms for detecting foreign RNA in the cytoplasm during viral 1128 infection has advanced substantially in recent years. This lays the ground for the development 1129 of new antivirals, vaccines and vaccine adjuvants, as exemplified in the exploration of RNA 1130 agonists of RIG-I and PACT as vaccine adjuvants, and the test of NS1-deleted IAV strains as 1131 vaccines. Cytoplasmic RNA sensors ranging from the prototypic member RIG-I to the newly 1132 identified PARP9 and SAFA operate in a discrete and coordinated manner to accomplish the 1133 very sophisticated task of RNA sensing. The RNA sensors partner with various RNA-binding 1134 proteins to fine-tune their sensing activity so that PAMP recognition could be accurate and 1135 the innate antiviral response would be activated with high specificity and the right magnitude.

1136 As more and more RNA sensors and their RNA-binding protein partners have been found, 1137 cross-talk and orchestration of different RNA sensing pathways emerge as the most important 1138 topics for further exploration. Biochemical and structural analysis of the RNA-protein and 
1139

1140

1141

1142

114

114

1146

1147

1148

1149

1151

1152

protein-protein complexes should also be revealing. The study of RNA sensing is also highly relevant to SARS-CoV-2 research, which has become one of the top priorities in the middle of the ongoing pandemic of COVID-19. Key questions concerning RNA sensing and SARS-CoV-2 include how SARS-CoV-2 RNA is sensed, what PAMPs are sensed by what PRRs, how SARSCoV-2 antagonizes host RNA sensing, and what implications the IFN antagonism of SARS-CoV2 has in pathogenesis, antiviral and vaccine development. New insights into these questions will not only derive new knowledge in SARS-CoV-2-host interaction, but also reveal new strategies for COVID-19 prevention and intervention.

\section{ACKNOWLEDGMENTS}

We thank Hinson Cheung and Kitty Fung for their critical reading of the manuscript. Work in our laboratory was supported by RGC (C7142-20GF and T11-709/21-N to D.-Y.J.) and HMRF (19181002 to C.-P.C.). 
1154

1155

1156

1157

1158

1159

1160

1161

1162

1163

1164

1165

1166

1167

1168

1169

1170

1171

1172

1173

1174

1175

1176

1177

1178

1179

1180

1181

1182

1183

1184

1185

1186

1187

1188

1189

1190

1191

1192

1193

1194

1195

1196

1197

1198

1199

1200

1201

Allen IC, Moore CB, Schneider M, Lei Y, Davis BK, Scull MA, Gris D, Roney KE, Zimmermann AG, Bowzard JB et al. 2011. NLRX1 protein attenuates inflammatory responses to infection by interfering with the RIG-I-MAVS and TRAF6-NF-KB signaling pathways. Immunity 34: 854-865.

Allen IC, Scull MA, Moore CB, Holl EK, McElvania-TeKippe E, Taxman DJ, Guthrie EH, Pickles RJ, Ting JP. 2009. The NLRP3 inflammasome mediates in vivo innate immunity to influenza $A$ virus through recognition of viral RNA. Immunity 30: 556-565.

Bajad P, Ebner F, Amman F, Szabo B, Kapoor U, Manjali G, Hildebrandt A, Janisiw MP, Jantsch MF. 2020. An internal deletion of ADAR rescued by MAVS deficiency leads to a minute phenotype. Nucleic Acids Res 48: 3286-3303.

Banerjee A, Mitra P. 2020. Ebola Virus VP35 Protein: Modeling of the Tetrameric Structure and an Analysis of Its Interaction with Human PKR. J Proteome Res 19: 4533-4542.

Banerjee S, Chakrabarti A, Jha BK, Weiss SR, Silverman RH. 2014. Cell-type-specific effects of RNase L on viral induction of beta interferon. mBio 5: e00856-00814.

Bauernfried S, Scherr MJ, Pichlmair A, Duderstadt KE, Hornung V. 2021. Human NLRP1 is a sensor for double-stranded RNA. Science 371: eabd0811.

Beachboard DC, Horner SM. 2016. Innate immune evasion strategies of DNA and RNA viruses. Curr Opin Microbiol 32: 113-119.

Berg RK, Melchjorsen J, Rintahaka J, Diget E, Soby S, Horan KA, Gorelick RJ, Matikainen S, Larsen CS, Ostergaard L et al. 2012. Genomic HIV RNA induces innate immune responses through RIG-Idependent sensing of secondary-structured RNA. PLOS ONE 7: e29291.

Berke IC, Modis Y. 2012. MDA5 cooperatively forms dimers and ATP-sensitive filaments upon binding double-stranded RNA. EMBO J 31: 1714-1726.

Bick MJ, Carroll JW, Gao G, Goff SP, Rice CM, MacDonald MR. 2003. Expression of the zinc-finger antiviral protein inhibits alphavirus replication. J Virol 77: 11555-11562.

Bidet K, Dadlani D, Garcia-Blanco MA. 2014. G3BP1, G3BP2 and CAPRIN1 are required for translation of interferon stimulated mRNAs and are targeted by a dengue virus non-coding RNA. PLOS Pathog 10: e1004242.

Boehmer DFR, Formisano S, de Oliveira Mann CC, Mueller SA, Kluge M, Metzger P, Rohlfs M, Horth C, Kocheise L, Lichtenthaler SF et al. 2021. OAS1/RNase L executes RIG-I ligand-dependent tumor cell apoptosis. Sci Immunol 6: eabe2550.

Brault M, Olsen TM, Martinez J, Stetson DB, Oberst A. 2018. Intracellular nucleic acid sensing triggers necroptosis through synergistic type I IFN and TNF signaling. J Immunol 200: 2748-2756.

Brisse M, Ly H. 2019. Comparative structure and function analysis of the RIG-I-like receptors: RIG-I and MDA5. Front Immunol 10: 1586.

Brisse M, Huang Q, Rahman M, Di D, Liang Y, Ly H. 2021. RIG-I and MDA5 protect mice from Pichinde virus infection by controlling viral replication and regulating immune responses to the infection. Front Immunol 12: 801811.

Broquet AH, Hirata Y, McAllister CS, Kagnoff MF. 2011. RIG-I/MDA5/MAVS are required to signal a protective IFN response in rotavirus-infected intestinal epithelium. J Immunol 186: 1618-1626.

Bruns A, Leser G, Lamb R, Horvath C. 2014. The Innate immune sensor LGP2 activates antiviral signaling by regulating MDA5-RNA interaction and filament assembly. Mol Cell 55: 771-781.

Bruns AM, Horvath CM. 2015. LGP2 synergy with MDA5 in RLR-mediated RNA recognition and antiviral signaling. Cytokine 74: 198-206.

Bruns AM, Pollpeter D, Hadizadeh N, Myong S, Marko JF, Horvath CM. 2013. ATP hydrolysis enhances RNA recognition and antiviral signal transduction by the innate immune sensor, laboratory of genetics and physiology 2 (LGP2). J Biol Chem 288: 938-946.

Buchet-Poyau K, Courchet J, Le Hir H, Seraphin B, Scoazec JY, Duret L, Domon-Dell C, Freund JN, Billaud M. 2007. Identification and characterization of human Mex-3 proteins, a novel family of 
evolutionarily conserved RNA-binding proteins differentially localized to processing bodies. Nucleic Acids Res 35: 1289-1300.

Buers I, Nitschke Y, Rutsch F. 2016. Novel interferonopathies associated with mutations in RIG-I like receptors. Cytokine Growth Factor Rev 29: 101-107.

Cadena C, Ahmad S, Xavier A, Willemsen J, Park S, Park JW, Oh S-W, Fujita T, Hou F, Binder M et al. 2019. Ubiquitin-dependent and -independent roles of E3 Ligase RIPLET in innate immunity. Cell 177: 1187-1200.e16.

Castanier C, Zemirli N, Portier A, Garcin D, Bidère N, Vazquez A, Arnoult D. 2012. MAVS ubiquitination by the E3 ligase TRIM25 and degradation by the proteasome is involved in type I interferon production after activation of the antiviral RIG-I-like receptors. BMC Biol 10: 44.

Cao L, Liu S, Li Y, Yang G, Luo Y, Li S, Du H, Zhao Y, Wang D, Chen J et al. 2019. The nuclear matrix protein SAFA surveils viral rna and facilitates immunity by activating antiviral enhancers and super-enhancers. Cell Host Microbe 26: 369-384.e8.

Carneiro LA, Magalhaes JG, Tattoli I, Philpott DJ, Travassos LH. 2008. Nod-like proteins in inflammation and disease. J Pathol 214: 136-148.

Chakrabarti A, Banerjee S, Franchi L, Loo YM, Gale M, Jr., Núñez G, Silverman RH. 2015. RNase L activates the NLRP3 inflammasome during viral infections. Cell Host Microbe 17: 466-477.

Chan CP, Yuen CK, Cheung PH, Fung SY, Lui PY, Chen H, Kok KH, Jin DY. 2018. Antiviral activity of double-stranded RNA-binding protein PACT against influenza A virus mediated via suppression of viral RNA polymerase. FASEB J 32: 4380-4393.

Chan YK, Gack MU. 2016. Viral evasion of intracellular DNA and RNA sensing. Nat Rev Microbiol 14: 360-373.

Chatterjee S, Basler CF, Amarasinghe GK, Leung DW. 2016. Molecular mechanisms of innate immune inhibition by non-segmented negative-sense RNA viruses. J Mol Biol 428: 3467-3482.

Chattopadhyay S, Kuzmanovic T, Zhang Y, Wetzel JL, Sen GC. 2016. Ubiquitination of the transcription factor IRF-3 activates RIPA, the apoptotic pathway that protects mice from viral pathogenesis. Immunity 44: 1151-1161.

Chattopadhyay S, Marques JT, Yamashita M, Peters KL, Smith K, Desai A, Williams BR, Sen GC. 2010. Viral apoptosis is induced by IRF-3-mediated activation of Bax. EMBO J 29: 1762-1773.

Chen CX, Cho DS, Wang Q, Lai F, Carter KC, Nishikura K. 2000. A third member of the RNA-specific adenosine deaminase gene family, ADAR3, contains both single- and double-stranded RNA binding domains. RNA 6: 755-767.

Chen S, Xu Y, Zhang K, Wang X, Sun J, Gao G, Liu Y. 2012. Structure of N-terminal domain of ZAP indicates how a zinc-finger protein recognizes complex RNA. Nat Struct Mol Biol 19: 430-435.

Chen X, Zhao Q, Xie Q, Xing Y, Chen Z. 2018. MCPIP1 negatively regulate cellular antiviral innate immune responses through DUB and disruption of TRAF3-TBK1-IKKepsilon complex. Biochem Biophys Res Commun 503: 830-836.

Chendrimada TP, Gregory RI, Kumaraswamy E, Norman J, Cooch N, Nishikura K, Shiekhattar R. 2005. TRBP recruits the Dicer complex to Ago2 for microRNA processing and gene silencing. Nature 436: 740-744.

Cheung PH, Lee TT, Chan CP, Jin DY. 2020a. Influenza A virus PB1-F2 protein: An ambivalent innate immune modulator and virulence factor. J Leukoc Biol 107: 763-771.

Cheung PH, Lee TT, Kew C, Chen H, Yuen KY, Chan CP, Jin DY. 2020b. Virus subtype-specific suppression of MAVS aggregation and activation by PB1-F2 protein of influenza A (H7N9) virus. PLoS Pathog 16: e1008611.

Cheung PH, Ye ZW, Lee TT, Chen H, Chan CP, Jin DY. 2020c. PB1-F2 protein of highly pathogenic influenza A (H7N9) virus selectively suppresses RNA-induced NLRP3 inflammasome activation through inhibition of MAVS-NLRP3 interaction. J Leukoc Biol 108: 1655-1663.

Chiang JJ, Sparrer KMJ, van Gent M, Lassig C, Huang T, Osterrieder N, Hopfner KP, Gack MU. 2018. Viral unmasking of cellular 5S rRNA pseudogene transcripts induces RIG-I-mediated immunity. Nat Immunol 19: 53-62. 
Choudhury NR, Heikel G, Trubitsyna M, Kubik P, Nowak JS, Webb S, Granneman S, Spanos C, Rappsilber J, Castello A. 2017. RNA-binding activity of TRIM25 is mediated by its PRY/SPRY domain and is required for ubiquitination. $B M C$ biology 15: 1-20.

Chow KT, Gale M, Jr., Loo YM. 2018. RIG-I and other RNA sensors in antiviral immunity. Annu Rev Immunol 36: 667-694.

Chukwurah E, Farabaugh KT, Guan BJ, Ramakrishnan P, Hatzoglou M. 2021. A tale of two proteins: PACT and PKR and their roles in inflammation. FEBS J 288: 6365-6391.

Clerzius G, Shaw E, Daher A, Burugu S, Gelinas JF, Ear T, Sinck L, Routy JP, Mouland AJ, Patel RC et al. 2013. The PKR activator, PACT, becomes a PKR inhibitor during HIV-1 replication. Retrovirology 10: 96.

Cobos Jimenez V, Martinez FO, Booiman T, van Dort KA, van de Klundert MA, Gordon S, Geijtenbeek TB, Kootstra NA. 2015. G3BP1 restricts HIV-1 replication in macrophages and T-cells by sequestering viral RNA. Virology 486: 94-104.

Corridoni D, Arseneau KO, Cifone MG, Cominelli F. 2014. The dual role of nod-like receptors in mucosal innate immunity and chronic intestinal inflammation. Front Immunol 5: 317.

Da Costa LS, Outlioua A, Anginot A, Akarid K, Arnoult D. 2019. RNA viruses promote activation of the NLRP3 inflammasome through cytopathogenic effect-induced potassium efflux. Cell Death Disease 10: 346.

Daffis S, Szretter KJ, Schriewer J, Li J, Youn S, Errett J, Lin TY, Schneller S, Zust R, Dong H et al. 2010. 2'O methylation of the viral mRNA cap evades host restriction by IFIT family members. Nature 468: 452-456.

Daniels BP, Kofman SB, Smith JR, Norris GT, Snyder AG, Kolb JP, Gao X, Locasale JW, Martinez J, Gale M, Jr. et al. 2019. The Nucleotide Sensor ZBP1 and Kinase RIPK3 Induce the Enzyme IRG1 to Promote an Antiviral Metabolic State in Neurons. Immunity 50: 64-76 e64.

Dar AC, Dever TE, Sicheri F. 2005. Higher-order substrate recognition of elF2alpha by the RNAdependent protein kinase PKR. Cell 122: 887-900.

Deddouche S, Goubau D, Rehwinkel J, Chakravarty P, Begum S, Maillard PV, Borg A, Matthews N, Feng Q, van Kuppeveld FJ et al. 2014. Identification of an LGP2-associated MDA5 agonist in picornavirus-infected cells. elife 3: e01535.

Dey M, Cao C, Dar AC, Tamura T, Ozato K, Sicheri F, Dever TE. 2005. Mechanistic link between PKR dimerization, autophosphorylation, and elF2alpha substrate recognition. Cell 122: 901-913.

Diamond MS, Farzan M. 2013. The broad-spectrum antiviral functions of IFIT and IFITM proteins. Nat Rev Immunol 13: 46-57.

Dickerman BK, White CL, Kessler PM, Sadler AJ, Williams BR, Sen GC. 2015. The protein activator of protein kinase $\mathrm{R}, \mathrm{PACT} / \mathrm{RAX}$, negatively regulates protein kinase $\mathrm{R}$ during mouse anterior pituitary development. FEBS J 282: 4766-4781.

Ding Z, Fang L, Yuan S, Zhao L, Wang X, Long S, Wang M, Wang D, Foda MF, Xiao S. 2017. The nucleocapsid proteins of mouse hepatitis virus and severe acute respiratory syndrome coronavirus share the same IFN-beta antagonizing mechanism: attenuation of PACT-mediated RIG-I/ MDA5 activation. Oncotarget 8: 49655-49670.

Drutman SB, Haerynck F, Zhong FL, Hum D, Hernandez NJ, Belkaya S, Rapaport F, de Jong SJ, Creytens D, Tavernier SJ et al. 2019. Homozygous NLRP1 gain-of-function mutation in siblings with a syndromic form of recurrent respiratory papillomatosis. Proc Natl Acad Sci U S A 116: 1905519063.

Duic I, Tadakuma H, Harada Y, Yamaue R, Deguchi K, Suzuki Y, Yoshimura SH, Kato H, Takeyasu K, Fujita T. 2020. Viral RNA recognition by LGP2 and MDA5, and activation of signaling through stepby-step conformational changes. Nucleic Acids Res 48: 11664-11674.

Dunker W, Ye X, Zhao Y, Liu L, Richardson A, Karijolich J. 2021. TDP-43 prevents endogenous RNAs from triggering a lethal RIG-I-dependent interferon response. Cell Rep 35: 108976. 
Edwards MR, Liu G, Mire CE, Sureshchandra S, Luthra P, Yen B, Shabman RS, Leung DW, Messaoudi I, Geisbert TW et al. 2016. Differential regulation of interferon responses by Ebola and Marburg virus VP35 proteins. Cell Rep 14: 1632-1640.

Esser-Nobis K, Hatfield LD, Gale M, Jr. 2020. Spatiotemporal dynamics of innate immune signaling via RIG-I-like receptors. Proc Natl Acad Sci U S A 117: 15778-15788.

Fan L, Briese T, Lipkin WI. 2010. Z proteins of New World arenaviruses bind RIG-I and interfere with type I interferon induction. J Virol 84: 1785-1791.

Fan X, Jin T. 2019. Structures of RIG-I-like receptors and insights into viral RNA sensing. Adv Exp Med Biol 1172: 157-188.

Farabaugh KT, Krokowski D, Guan BJ, Gao Z, Gao XH, Wu J, Jobava R, Ray G, de Jesus TJ, Bianchi MG et al. 2020. PACT-mediated PKR activation acts as a hyperosmotic stress intensity sensor weakening osmoadaptation and enhancing inflammation. eLife 9: e52241.

Feng H, Lenarcic EM, Yamane D, Wauthier E, Mo J, Guo H, McGivern DR, Gonzalez-Lopez O, Misumi I, Reid LM et al. 2017. NLRX1 promotes immediate IRF1-directed antiviral responses by limiting dsRNA-activated translational inhibition mediated by PKR. Nat Immunol 18: 1299-1309.

Feng Q, Hato SV, Langereis MA, Zoll J, Virgen-Slane R, Peisley A, Hur S, Semler BL, van Rij RP, van Kuppeveld FJM. 2012. MDA5 detects the double-stranded RNA replicative form in picornavirus-infected cells. Cell Rep 2: 1187-1196.

Fensterl V, Sen GC. 2015. Interferon-induced Ifit proteins: Their role in viral pathogenesis. J Virol 89: 2462-2468.

Ficarelli M, Antzin-Anduetza I, Hugh-White R, Firth AE, Sertkaya H, Wilson H, Neil SJD, Schulz R, Swanson CM. 2020. CpG dinucleotides inhibit HIV-1 replication through zinc finger antiviral protein (ZAP)-dependent and -independent mechanisms. J Virol 94: e01337-19.

Ficarelli M, Neil SJD, Swanson CM. 2021. Targeted restriction of viral gene expression and replication by the ZAP antiviral system. Annu Rev Virol 8: 265-283.

Ficarelli M, Wilson H, Pedro Galao R, Mazzon M, Antzin-Anduetza I, Marsh M, Neil SJ, Swanson CM. 2019. KHNYN is essential for the zinc finger antiviral protein (ZAP) to restrict HIV-1 containing clustered CpG dinucleotides. eLife 8: e46767.

Fleith RC, Mears HV, Leong XY, Sanford TJ, Emmott E, Graham SC, Mansur DS, Sweeney TR. 2018. IFIT3 and IFIT2/3 promote IFIT1-mediated translation inhibition by enhancing binding to non-self RNA. Nucleic Acids Res 46: 5269-5285.

Franchi L, Eigenbrod T, Munoz-Planillo R, Ozkurede U, Kim YG, Arindam C, Gale M, Jr., Silverman RH, Colonna M, Akira S et al. 2014. Cytosolic double-stranded RNA activates the NLRP3 inflammasome via MAVS-induced membrane permeabilization and $\mathrm{K}^{+}$efflux. J Immunol 193: 4214-4222.

Fredericksen BL, Keller BC, Fornek J, Katze MG, Gale M, Jr. 2008. Establishment and maintenance of the innate antiviral response to West Nile Virus involves both RIG-I and MDA5 signaling through IPS-1. J Virol 82: 609-616.

Fu M, Blackshear PJ. 2017. RNA-binding proteins in immune regulation: a focus on $\mathrm{CCCH}$ zinc finger proteins. Nature Reviews Immunology 17: 130-143.

Fullam A, Schroder M. 2013. DExD/H-box RNA helicases as mediators of anti-viral innate immunity and essential host factors for viral replication. Biochim Biophys Acta 1829: 854-865.

Fung SY, Yuen KS, Ye ZW, Chan CP, Jin DY. 2020. A tug-of-war between severe acute respiratory syndrome coronavirus 2 and host antiviral defence: lessons from other pathogenic viruses. Emerg Microbes Infect 9: 558-570.

Gack MU, Shin YC, Joo CH, Urano T, Liang C, Sun L, Takeuchi O, Akira S, Chen Z, Inoue S et al. 2007. TRIM25 RING-finger E3 ubiquitin ligase is essential for RIG-I-mediated antiviral activity. Nature 446: 916-920.

Gal-Ben-Ari S, Barrera I, Ehrlich M, Rosenblum K. 2018. PKR: A kinase to remember. Front Mol Neurosci 11: 480. 
Gao G, Guo X, Goff SP. 2002. Inhibition of retroviral RNA production by ZAP, a CCCH-type zinc finger protein. Science 297: 1703-1706.

Garzia A, Jafarnejad SM, Meyer C, Chapat C, Gogakos T, Morozov P, Amiri M, Shapiro M, Molina H, Tuschl T et al. 2017. The E3 ubiquitin ligase and RNA-binding protein ZNF598 orchestrates ribosome quality control of premature polyadenylated mRNAs. Nat Commun 8: 16056.

George CX, Li Z, Okonski KM, Toth AM, Wang Y, Samuel CE. 2009. Tipping the balance: antagonism of PKR kinase and ADAR1 deaminase functions by virus gene products. J Interferon Cytokine Res 29: 477-487.

Goubau D, Schlee M, Deddouche S, Pruijssers AJ, Zillinger T, Goldeck M, Schuberth C, Van der Veen AG, Fujimura T, Rehwinkel J et al. 2014. Antiviral immunity via RIG-I-mediated recognition of RNA bearing 5'-diphosphates. Nature 514: 372-375.

Gringhuis SI, Hertoghs N, Kaptein TM, Zijlstra-Willems EM, Sarrami-Fooroshani R, Sprokholt JK, Van Teijlingen NH, Kootstra NA, Booiman T, Van Dort KA et al. 2017. HIV-1 blocks the signaling adaptor MAVS to evade antiviral host defense after sensing of abortive HIV-1 RNA by the host helicase DDX3. Nat Immunol 18: 225-235.

Grunvogel O, Esser-Nobis K, Reustle A, Schult P, Muller B, Metz P, Trippler M, Windisch MP, Frese M, Binder $\mathrm{M}$ et al. 2015. DDX60L is an interferon-stimulated gene product restricting hepatitis $C$ virus replication in cell culture. J Virol 89: 10548-10568.

Guo H, Konig R, Deng M, Riess M, Mo J, Zhang L, Petrucelli A, Yoh SM, Barefoot B, Samo M et al. 2016. NLRX1 sequesters STING to negatively regulate the interferon response, thereby facilitating the replication of HIV-1 and DNA viruses. Cell Host Microbe 19: 515-528.

Guo HC, Jin Y, Zhi XY, Yan D, Sun SQ. 2015. NLRP3 inflammasome activation by viroporins of animal viruses. Viruses 7: 3380-3391.

Guo J, Peters KL, Sen GC. 2000. Induction of the human protein P56 by interferon, double-stranded RNA, or virus infection. Virology 267: 209-219.

Habjan M, Andersson I, Klingstrom J, Schumann M, Martin A, Zimmermann P, Wagner V, Pichlmair A, Schneider $U$, Muhlberger $E$ et al. 2008. Processing of genome 5 ' termini as a strategy of negative-strand RNA viruses to avoid RIG-I-dependent interferon induction. PLOS ONE 3: e2032.

Habjan M, Hubel P, Lacerda L, Benda C, Holze C, Eberl CH, Mann A, Kindler E, Gil-Cruz C, Ziebuhr J et al. 2013. Sequestration by IFIT1 impairs translation of 2'O-unmethylated capped RNA. PLoS Pathog 9: e1003663.

Han Y, Donovan J, Rath S, Whitney G, Chitrakar A, Korennykh A. 2014. Structure of human RNase L reveals the basis for regulated RNA decay in the IFN response. Science 343: 1244-1248.

Hartner JC, Walkley CR, Lu J, Orkin SH. 2009. ADAR1 is essential for the maintenance of hematopoiesis and suppression of interferon signaling. Nat Immunol 10: 109-115.

Hatakeyama S. 2017. TRIM family proteins: Roles in autophagy, immunity, and carcinogenesis. Trends Biochem Sci 42: 297-311.

Hayman TJ, Hsu AC, Kolesnik TB, Dagley LF, Willemsen J, Tate MD, Baker PJ, Kershaw NJ, Kedzierski L, Webb Al et al. 2019. RIPLET, and not TRIM25, is required for endogenous RIG-I-dependent antiviral responses. Immunol Cell Biol 97: 840-852.

He S, Zhao J, Song S, He X, Minassian A, Zhou Y, Zhang J, Brulois K, Wang Y, Cabo J et al. 2015. Viral pseudo-enzymes activate RIG-I via deamidation to evade cytokine production. Mol Cell 58: 134-146.

Heraud-Farlow JE, Walkley CR. 2020. What do editors do? Understanding the physiological functions of A-to-I RNA editing by adenosine deaminase acting on RNAs. Open Biology 10: 200085.

Herbert A. 2021. To "Z" or not to "Z": Z-RNA, self-recognition, and the MDA5 helicase. PLoS Genet 17: e1009513.

Heyam A, Coupland CE, Degut C, Haley RA, Baxter NJ, Jakob L, Aguiar PM, Meister G, Williamson MP, Lagos D et al. 2017. Conserved asymmetry underpins homodimerization of Dicer-associated double-stranded RNA-binding proteins. Nucleic Acids Res 45: 12577-12584. 
Heyam A, Lagos D, Plevin M. 2015. Dissecting the roles of TRBP and PACT in double-stranded RNA recognition and processing of noncoding RNAs. Wiley Interdiscip Rev RNA 6: 271-289.

Ho TH, Kew C, Lui PY, Chan CP, Satoh T, Akira S, Jin DY, Kok KH. 2016. PACT- and RIG-I-dependent activation of type I interferon production by a defective interfering RNA derived from measles virus vaccine. J Virol 90: 1557-1568.

Hong M, Yoon SI, Wilson IA. 2012. Structure and functional characterization of the RNA-binding element of the NLRX1 innate immune modulator. Immunity 36: 337-347.

Hooftman A, Angiari S, Hester S, Corcoran SE, Runtsch MC, Ling C, Ruzek MC, Slivka PF, McGettrick AF, Banahan $\mathrm{K}$ et al. 2020. The Immunomodulatory Metabolite Itaconate Modifies NLRP3 and Inhibits Inflammasome Activation. Cell Metab 32: 468-478 e467.

Hornung V, Ellegast J, Kim S, Brzozka K, Jung A, Kato H, Poeck H, Akira S, Conzelmann KK, Schlee M et al. 2006. 5'-Triphosphate RNA is the ligand for RIG-I. Science 314: 994-997.

Hou P, Yang K, Jia P, Liu L, Lin Y, Li Z, Li J, Chen S, Guo S, Pan J et al. 2020. A novel selective autophagy receptor, CCDC50, delivers $\mathrm{K} 63$ polyubiquitination-activated RIG-I/MDA5 for degradation during viral infection. Cell Res 31: 62-79.

Hovanessian AG, Justesen J. 2007. The human 2'-5'oligoadenylate synthetase family: unique interferon-inducible enzymes catalyzing 2'-5' instead of 3'-5' phosphodiester bond formation. Biochimie 89: 779-788.

Huang H, Zhao J, Wang TY, Zhang S, Zhou Y, Rao Y, Qin C, Liu Y, Chen Y, Xia Z et al. 2021. Speciesspecific deamidation of RIG-I reveals collaborative action between viral and cellular deamidases in HSV-1 lytic replication. mBio 12: e00115-21.

Hull CM, Bevilacqua PC. 2016. Discriminating self and non-self by RNA: Roles for RNA structure, misfolding, and modification in regulating the innate immune sensor PKR. Acc Chem Res 49: 1242-1249.

Hur S. 2019. Double-stranded RNA sensors and modulators in innate immunity. Annu Rev Immuno/ 37: 349-375.

Ichinohe T, Pang IK, Iwasaki A. 2010. Influenza virus activates inflammasomes via its intracellular M2 ion channel. Nat Immunol 11: 404-410.

Ikegame S, Takeda M, Ohno S, Nakatsu Y, Nakanishi Y, Yanagi Y. 2010. Both RIG-I and MDA5 RNA helicases contribute to the induction of alpha/beta interferon in measles virus-infected human cells. J Virol 84: 372-379.

Iwamura T, Yoneyama M, Koizumi N, Okabe Y, Namiki H, Samuel CE, Fujita T. 2001. PACT, a doublestranded RNA binding protein acts as a positive regulator for type I interferon gene induced by Newcastle disease virus. Biochem Biophys Res Commun 282: 515-523.

Jaworska J, Coulombe F, Downey J, Tzelepis F, Shalaby K, Tattoli I, Berube J, Rousseau S, Martin JG, Girardin SE et al. 2014. NLRX1 prevents mitochondrial induced apoptosis and enhances macrophage antiviral immunity by interacting with influenza virus PB1-F2 protein. Proc Natl Acad Sci U S A 111: E2110-2119.

Jiang M, Zhang S, Yang Z, Lin H, Zhu J, Liu L, Wang W, Liu S, Liu W, Ma Y et al. 2018. Self-recognition of an inducible host IncRNA by RIG-I feedback restricts innate immune response. Cell 173: 906 919.e13.

Kane M, Zang TM, Rihn SJ, Zhang F, Kueck T, Alim M, Schoggins J, Rice CM, Wilson SJ, Bieniasz PD. 2016. Identification of interferon-stimulated genes with antiretroviral activity. Cell Host Microbe 20: 392-405.

Kanneganti TD, Body-Malapel M, Amer A, Park JH, Whitfield J, Franchi L, Taraporewala ZF, Miller D, Patton JT, Inohara N et al. 2006. Critical role for Cryopyrin/Nalp3 in activation of caspase-1 in response to viral infection and double-stranded RNA. J Biol Chem 281: 36560-36568.

Kato H, Takeuchi O, Mikamo-Satoh E, Hirai R, Kawai T, Matsushita K, Hiiragi A, Dermody TS, Fujita T, Akira S. 2008. Length-dependent recognition of double-stranded ribonucleic acids by retinoic acid-inducible gene-I and melanoma differentiation-associated gene 5. J Exp Med 205: 16011610. 
Kato H, Takeuchi O, Sato S, Yoneyama M, Yamamoto M, Matsui K, Uematsu S, Jung A, Kawai T, Ishii KJ et al. 2006. Differential roles of MDA5 and RIG-I helicases in the recognition of RNA viruses. Nature 441: 101-105.

Kato K, Ahmad S, Zhu Z, Young JM, Mu X, Park S, Malik HS, Hur S. 2021. Structural analysis of RIG-I-like receptors reveals ancient rules of engagement between diverse RNA helicases and TRIM ubiquitin ligases. Mol Cell 81: 599-613 e598.

Kell AM, Gale M, Jr. 2015. RIG-I in RNA virus recognition. Virology 479-480: 110-121.

Kew C, Lui PY, Chan CP, Liu X, Au SW, Mohr I, Jin DY, Kok KH. 2013. Suppression of PACT-induced type I interferon production by herpes simplex virus 1 Us11 protein. J Virol 87: 13141-13149.

Kim MJ, Hwang SY, Imaizumi T, Yoo JY. 2008. Negative feedback regulation of RIG-I-mediated antiviral signaling by interferon-induced ISG15 conjugation. J Virol 82: 1474-1483.

Kim SS, Sze L, Liu C, Lam KP. 2019. The stress granule protein G3BP1 binds viral dsRNA and RIG-I to enhance interferon-beta response. J Biol Chem 294: 6430-6438.

King PH, Chen CY. 2014. Role of KSRP in control of type I interferon and cytokine expression. J Interferon Cytokine Res 34: 267-274.

Kok KH, Lui PY, Ng MH, Siu KL, Au SW, Jin DY. 2011. The double-stranded RNA-binding protein PACT functions as a cellular activator of RIG-I to facilitate innate antiviral response. Cell Host Microbe 9: 299-309.

Kok KH, Ng MH, Ching YP, Jin DY. 2007. Human TRBP and PACT directly interact with each other and associate with dicer to facilitate the production of small interfering RNA. J Biol Chem 282: 17649-17657.

Komuro A, Horvath CM. 2006. RNA- and virus-independent inhibition of antiviral signaling by RNA helicase LGP2. J Virol 80: 12332-12342.

Krishna SS, Majumdar I, Grishin NV. 2003. Structural classification of zinc fingers: survey and summary. Nucleic Acids Res 31: 532-550.

Kristiansen H, Gad HH, Eskildsen-Larsen S, Despres P, Hartmann R. 2011. The oligoadenylate synthetase family: an ancient protein family with multiple antiviral activities. J Interferon Cytokine Res 31: 41-47.

Krug RM. 2015. Functions of the influenza A virus NS1 protein in antiviral defense. Curr Opin Virol 12: 1-6.

Kuniyoshi K, Takeuchi O, Pandey S, Satoh T, Iwasaki H, Akira S, Kawai T. 2014. Pivotal role of RNAbinding E3 ubiquitin ligase MEX3C in RIG-I-mediated antiviral innate immunity. Proc Natl Acad Sci U S A 111: 5646-5651.

Kuriakose T, Man SM, Subbarao Malireddi RK, Karki R, Kesavardhana S, Place DE, Neale G, Vogel P, Kanneganti TD. 2016. ZBP1/DAI is an innate sensor of influenza virus triggering the NLRP3 inflammasome and programmed cell death pathways. Sci Immunol 1: aag2045.

Kurtzman DJB, Vleugels RA. 2018. Anti-melanoma differentiation-associated gene 5 (MDA5) dermatomyositis: A concise review with an emphasis on distinctive clinical features. J Am Acad Dermatol 78: 776-785.

Lamers MM, Van Den Hoogen BG, Haagmans BL. 2019. ADAR1: “Editor-in-Chief” of cytoplasmic innate immunity. Front Immunol 10: 1763.

Lang X, Tang T, Jin T, Ding C, Zhou R, Jiang W. 2017. TRIM65-catalized ubiquitination is essential for MDA5-mediated antiviral innate immunity. J Exp Med 214: 459-473.

Le Voyer T, Neehus AL, Yang R, Ogishi M, Rosain J, Alroqi F, Alshalan M, Blumental S, Al Ali F, Khan T et al. 2021. Inherited deficiency of stress granule ZNFX1 in patients with monocytosis and mycobacterial disease. Proc Natl Acad Sci U S A 118: e2102804118.

Lee H, Komano J, Saitoh Y, Yamaoka S, Kozaki T, Misawa T, Takahama M, Satoh T, Takeuchi O, Yamamoto $\mathrm{N}$ et al. 2013a. Zinc-finger antiviral protein mediates retinoic acid inducible gene Ilike receptor-independent antiviral response to murine leukemia virus. Proc Natl Acad Sci U S A 110: $12379-12384$. 
1504

1505

1506

1507

1508

1509

1510

1511

1512

1513

1514

1515

1516

1517

1518

1519

1520

1521

1522

1523

1524

1525

1526

1527

1528

1529

1530

1531

1532

1533

1534

1535

1536

1537

1538

1539

1540

1541

1542

1543

1544

1545

1546

1547

1548

1549

1550

1551

1552

1553
Lee HY, Zhou K, Smith AM, Noland CL, Doudna JA. 2013b. Differential roles of human Dicer-binding proteins TRBP and PACT in small RNA processing. Nucleic Acids Res 41: 6568-6576.

Lee S, Karki R, Wang Y, Nguyen LN, Kalathur RC, Kanneganti TD. 2021. AIM2 forms a complex with pyrin and ZBP1 to drive PANoptosis and host defence. Nature 597: 415-419.

Lee Y, Hur I, Park SY, Kim YK, Suh MR, Kim VN. 2006. The role of PACT in the RNA silencing pathway. $E M B O$ J 25: 522-532.

Lei Y, Wen H, Ting JP. 2013. The NLR protein, NLRX1, and its partner, TUFM, reduce type I interferon, and enhance autophagy. Autophagy 9: 432-433.

Lei Y, Wen H, Yu Y, Taxman DJ, Zhang L, Widman DG, Swanson KV, Wen KW, Damania B, Moore CB et al. 2012. The mitochondrial proteins NLRX1 and TUFM form a complex that regulates type I interferon and autophagy. Immunity 36: 933-946.

Li J, Hu L, Liu Y, Huang L, Mu Y, Cai X, Weng C. 2015. DDX19A Senses Viral RNA and Mediates NLRP3Dependent Inflammasome Activation. J Immunol 195: 5732-5749.

Li J, Liu Y, Zhang X. 2010. Murine coronavirus induces type I interferon in oligodendrocytes through recognition by RIG-I and MDA5. J Virol 84: 6472-6482.

Li M, Yang J, Zhao Y, Song Y, Yin S, Guo J, Zhang H, Wang K, Wei L, Li S et al. 2020a. MCPIP1 inhibits Hepatitis $B$ virus replication by destabilizing viral RNA and negatively regulates the virusinduced innate inflammatory responses. Antiviral Res 174: 104705.

Li MM, Lau Z, Cheung P, Aguilar EG, Schneider WM, Bozzacco L, Molina H, Buehler E, Takaoka A, Rice CM et al. 2017. TRIM25 Enhances the Antiviral Action of Zinc-Finger Antiviral Protein (ZAP). PLoS Pathog 13: e1006145.

Li S, Li H, Zhang YL, Xin QL, Guan ZQ, Chen X, Zhang XA, Li XK, Xiao GF, Lozach PY et al. 2020b. SFTSV infection induces BAK/BAX-dependent mitochondrial DNA release to trigger NLRP3 inflammasome activation. Cell Rep 30: 4370-4385.e7.

Li S, Wang L, Fu B, Berman MA, Diallo A, Dorf ME. 2014. TRIM65 regulates microRNA activity by ubiquitination of TNRC6. Proc Natl Acad Sci U S A 111: 6970-6975.

Lian H, Wei J, Zang R, Ye W, Yang Q, Zhang XN, Chen YD, Fu YZ, Hu MM, Lei CQ et al. 2018a. ZCCHC3 is a co-sensor of cGAS for dsDNA recognition in innate immune response. Nat Commun 9: 3349.

Lian H, Zang R, Wei J, Ye W, Hu MM, Chen YD, Zhang XN, Guo Y, Lei CQ, Yang Q et al. 2018b. The zincfinger protein ZCCHC3 binds RNA and facilitates viral RNA sensing and activation of the RIG-Ilike receptors. Immunity 49: 438-448.e5.

Liddicoat BJ, Piskol R, Chalk AM, Ramaswami G, Higuchi M, Hartner JC, Li JB, Seeburg PH, Walkley CR. 2015. RNA editing by ADAR1 prevents MDA5 sensing of endogenous dsRNA as nonself. Science 349: $1115-1120$.

Limonta D, Dyna-Dagman L, Branton W, Mancinelli V, Makio T, Wozniak RW, Power C, Hobman TC. 2021. Nodosome inhibition as a novel broad-spectrum antiviral strategy against arboviruses, enteroviruses, and SARS-CoV-2. Antimicrob Agents Chemother 65: e0049121.

Lin H, Jiang M, Liu L, Yang Z, Ma Z, Liu S, Ma Y, Zhang L, Cao X. 2019. The long noncoding RNA Lnczc3h7a promotes a TRIM25-mediated RIG-I antiviral innate immune response. Nat Immunol 20: 812823.

Lin RJ, Chien HL, Lin SY, Chang BL, Yu HP, Tang WC, Lin YL. 2013. MCPIP1 ribonuclease exhibits broadspectrum antiviral effects through viral RNA binding and degradation. Nucleic Acids Res 41: 3314-3326.

Liu B, Li NL, Shen Y, Bao X, Fabrizio T, Elbahesh H, Webby RJ, Li K. 2016. The C-terminal tail of TRIM56 dictates antiviral restriction of influenza $A$ and $B$ viruses by impeding viral RNA synthesis. $J$ Virol 90: 4369-4382.

Liu BY, Yu XJ, Zhou CM. 2021a. SAFA initiates innate immunity against cytoplasmic RNA virus SFTSV infection. PLoS Pathog 17: e1010070.

Liu G, Gack MU. 2020. Distinct and orchestrated functions of RNA sensors in innate immunity. Immunity 53: 26-42. 
Liu G, Lee JH, Parker ZM, Acharya D, Chiang JJ, van Gent M, RiedI W, Davis-Gardner ME, Wies E, Chiang $C$ et al. 2021b. ISG15-dependent activation of the sensor MDA5 is antagonized by the SARSCoV-2 papain-like protease to evade host innate immunity. Nat Microbiol 6: 467-478.

Liu G, Lu Y, Thulasi Raman SN, Xu F, Wu Q, Li Z, Brownlie R, Liu Q, Zhou Y. 2018. Nuclear-resident RIGI senses viral replication inducing antiviral immunity. Nat Commun 9: 3199.

Liu G, Park HS, Pyo HM, Liu Q, Zhou Y. 2015. Influenza A virus panhandle structure is directly involved in RIG-I Activation and interferon induction. J Virol 89: 6067-6079.

Liu S, Chen J, Cai X, Wu J, Chen X, Wu YT, Sun L, Chen ZJ. 2013. MAVS recruits multiple ubiquitin E3 ligases to activate antiviral signaling cascades. eLife 2: e00785.

Liu Y, Lu N, Yuan B, Weng L, Wang F, Liu YJ, Zhang Z. 2014. The interaction between the helicase DHX33 and IPS-1 as a novel pathway to sense double-stranded RNA and RNA viruses in myeloid dendritic cells. Cell Mol Immunol 11: 49-57.

Lu H, Lu N, Weng L, Yuan B, Liu Y-J, Zhang Z. 2014. DHX15 senses double-stranded RNA in Myeloid dendritic cells. J Immunol 193: 1364-1372.

Lu HL, Liao F. 2013. Melanoma differentiation-associated gene 5 senses hepatitis B virus and activates innate immune signaling to suppress virus replication. J Immunol 191: 3264-3276.

Lui PY, Wong LR, Ho TH, Au SWN, Chan CP, Kok KH, Jin DY. 2017. PACT facilitates RNA-induced activation of MDA5 by promoting MDA5 oligomerization. J Immunol 199: 1846-1855.

Lumb JH, Popov LM, Ding S, Keith MT, Merrill BD, Greenberg HB, Carette JE, Li Q, Li JB. 2017. DDX6 represses aberrant activation of interferon-stimulated genes. Cell Rep 20: 819-831.

Luo D, Kohlway A, Pyle AM. 2013. Duplex RNA activated ATPases (DRAs): Platforms for RNA sensing, signaling and processing. RNA Biol 10: 111-120.

Lupfer C, Malik A, Kanneganti TD. 2015. Inflammasome control of viral infection. Curr Opin Virol 12: 38-46.

Lupfer C, Thomas PG, Kanneganti TD. 2014. Nucleotide oligomerization and binding domain 2dependent dendritic cell activation is necessary for innate immunity and optimal CD8+ T Cell responses to influenza A virus infection. J Virol 88: 8946-8955.

Luthra P, Ramanan P, Mire CE, Weisend C, Tsuda Y, Yen B, Liu G, Leung DW, Geisbert TW, Ebihara H et al. 2013. Mutual antagonism between the Ebola virus VP35 protein and the RIG-I activator PACT determines infection outcome. Cell Host Microbe 14: 74-84.

Ma Z, Moore R, Xu X, Barber GN. 2013. DDX24 negatively regulates cytosolic RNA-mediated innate immune signaling. PLoS Pathog 9: e1003721.

MacDonald MR, Machlin ES, Albin OR, Levy DE. 2007. The zinc finger antiviral protein acts synergistically with an interferon-induced factor for maximal activity against alphaviruses. $J$ Virol 81: 13509-13518.

Maelfait J, Liverpool L, Bridgeman A, Ragan KB, Upton JW, Rehwinkel J. 2017. Sensing of viral and endogenous RNA by ZBP1/DAI induces necroptosis. EMBO J 36: 2529-2543.

Maelfait J, Liverpool L, Rehwinkel J. 2020. Nucleic acid sensors and programmed cell death. J Mol Biol 432: 552-568.

Mahboubi H, Stochaj U. 2017. Cytoplasmic stress granules: Dynamic modulators of cell signaling and disease. Biochim Biophys Acta Mol Basis Dis 1863: 884-895.

Malik G, Zhou Y. 2020. Innate immune sensing of influenza A virus. Viruses 12: 755.

Mallery DL, McEwan WA, Bidgood SR, Towers GJ, Johnson CM, James LC. 2010. Antibodies mediate intracellular immunity through tripartite motif-containing 21 (TRIM21). Proc Natl Acad Sci U S A 107: 19985-19990.

Manivannan P, Siddiqui MA, Malathi K. 2020. RNase L amplifies interferon signaling by inducing protein kinase R-mediated antiviral stress granules. J Virol 94: e00205-20.

Mannion NM, Greenwood SM, Young R, Cox S, Brindle J, Read D, Nellåker C, Vesely C, Ponting CP, McLaughlin PJ et al. 2014. The RNA-Editing Enzyme ADAR1 Controls Innate Immune Responses to RNA. Cell Rep 9: 1482-1494. 
Mao R, Nie H, Cai D, Zhang J, Liu H, Yan R, Cuconati A, Block TM, Guo JT, Guo H. 2013. Inhibition of hepatitis $B$ virus replication by the host zinc finger antiviral protein. PLoS Pathog 9: e1003494.

Marq JB, Hausmann S, Luban J, Kolakofsky D, Garcin D. 2009. The double-stranded RNA binding domain of the vaccinia virus E3L protein inhibits both RNA- and DNA-induced activation of interferon beta. J Biol Chem 284: 25471-25478.

Marq JB, Hausmann S, Veillard N, Kolakofsky D, Garcin D. 2011. Short double-stranded RNAs with an overhanging 5' ppp-nucleotide, as found in arenavirus genomes, act as RIG-I decoys. J Biol Chem 286: 6108-6116.

Martin-Vicente M, Medrano LM, Resino S, Garcia-Sastre A, Martinez I. 2017. TRIM25 in the regulation of the antiviral innate immunity. Front Immunol 8: 1187.

Martinez-Gil L, Goff PH, Hai R, Garcia-Sastre A, Shaw ML, Palese P. 2013. A Sendai virus-derived RNA agonist of RIG-I as a virus vaccine adjuvant. J Virol 87: 1290-1300.

Martinon F, Burns K, Tschopp J. 2002. The inflammasome: a molecular platform triggering activation of inflammatory caspases and processing of prolL-beta. Mol Cell 10: 417-426.

Matsumiya T, Stafforini DM. 2010. Function and regulation of retinoic acid-inducible gene-I. Crit Rev Immunol 30: 489-513.

Matsushita K, Takeuchi O, Standley DM, Kumagai Y, Kawagoe T, Miyake T, Satoh T, Kato H, Tsujimura T, Nakamura $\mathrm{H}$ et al. 2009. Zc3h12a is an RNase essential for controlling immune responses by regulating mRNA decay. Nature 458: 1185-1190.

Maurano M, Snyder JM, Connelly C, Henao-Mejia J, Sidrauski C, Stetson DB. 2021. Protein kinase R and the integrated stress response drive immunopathology caused by mutations in the RNA deaminase ADAR1. Immunity 54: 1948-1960 e1945.

McEwan WA, Tam JC, Watkinson RE, Bidgood SR, Mallery DL, James LC. 2013. Intracellular antibodybound pathogens stimulate immune signaling via the Fc receptor TRIM21. Nat Immunol 14: 327-336.

Meagher JL, Takata M, Goncalves-Carneiro D, Keane SC, Rebendenne A, Ong H, Orr VK, MacDonald MR, Stuckey JA, Bieniasz PD et al. 2019. Structure of the zinc-finger antiviral protein in complex with RNA reveals a mechanism for selective targeting of CG-rich viral sequences. Proc Natl Acad Sci U S A 116: 24303-24309.

Meyer C, Garzia A, Mazzola M, Gerstberger S, Molina H, Tuschl T. 2018. The TIA1 RNA-binding protein family regulates EIF2AK2-mediated stress response and cell cycle progression. Mol Cell 69: 622-635 e626.

Minamitani T, Iwakiri D, Takada K. 2011. Adenovirus virus-associated RNAs induce type I interferon expression through a RIG-I-mediated pathway. J Virol 85: 4035-4040.

Mitoma H, Hanabuchi S, Kim T, Bao M, Zhang Z, Sugimoto N, Liu YJ. 2013. The DHX33 RNA Helicase Senses Cytosolic RNA and Activates the NLRP3 Inflammasome. Immunity 39: 123-135.

Miyashita M, Oshiumi H, Matsumoto M, Seya T. 2011. DDX60, a DEXD/H box helicase, is a novel antiviral factor promoting RIG-I-like receptor-mediated signaling. Mol Cell Biol 31: 3802-3819.

Montavon TC, Baldaccini M, Lefevre M, Girardi E, Chane-Woon-Ming B, Messmer M, Hammann P, Chicher J, Pfeffer S. 2021. Human DICER helicase domain recruits PKR and modulates its antiviral activity. PLoS Pathog 17: e1009549.

Moore CB, Bergstralh DT, Duncan JA, Lei Y, Morrison TE, Zimmermann AG, Accavitti-Loper MA, Madden VJ, Sun L, Ye Z et al. 2008. NLRX1 is a regulator of mitochondrial antiviral immunity. Nature 451: 573-577.

Moy RH, Cole BS, Yasunaga A, Gold B, Shankarling G, Varble A, Molleston JM, tenOever BR, Lynch KW, Cherry S. 2014. Stem-loop recognition by DDX17 facilitates miRNA processing and antiviral defense. Cell 158: 764-777.

Muller S, Moller P, Bick MJ, Wurr S, Becker S, Gunther S, Kummerer BM. 2007. Inhibition of filovirus replication by the zinc finger antiviral protein. J Virol 81: 2391-2400. 
Mura M, Combredet C, Najburg V, Sanchez David RY, Tangy F, Komarova AV. 2017. Nonencapsidated 5' copy-back defective interfering genomes produced by recombinant measles viruses are recognized by RIG-I and LGP2 but not MDA5. J Virol 91:e00643-17.

Myskiw C, Arsenio J, Booy EP, Hammett C, Deschambault Y, Gibson SB, Cao J. 2011. RNA species generated in vaccinia virus infected cells activate cell type-specific MDA5 or RIG-I dependent interferon gene transcription and PKR dependent apoptosis. Virology 413: 183-193.

Nasirudeen AM, Wong HH, Thien P, Xu S, Lam KP, Liu DX. 2011. RIG-I, MDA5 and TLR3 synergistically play an important role in restriction of dengue virus infection. PLoS Negl Trop Dis 5: e926.

Nchioua R, Kmiec D, Muller JA, Conzelmann C, Gross R, Swanson CM, Neil SJD, Stenger S, Sauter D, Munch J et al. 2020. SARS-CoV-2 is restricted by zinc finger antiviral protein despite preadaptation to the low-CpG environment in humans. mBio 11: e01930-20.

Nguyen NT, Now H, Kim WJ, Kim N, Yoo JY. 2016. Ubiquitin-like modifier FAT10 attenuates RIG-I mediated antiviral signaling by segregating activated RIG-I from its signaling platform. Sci Rep 6: 23377.

Nie Y, Hammond GL, Yang JH. 2007. Double-stranded RNA deaminase ADAR1 increases host susceptibility to virus infection. J Virol 81: 917-923.

Nogusa S, Thapa RJ, Dillon CP, Liedmann S, Oguin TH, 3rd, Ingram JP, Rodriguez DA, Kosoff R, Sharma S, Sturm O et al. 2016. RIPK3 activates parallel pathways of MLKL-driven necroptosis and FADD-mediated apoptosis to protect against influenza A virus. Cell Host Microbe 20: 13-24.

Noland CL, Doudna JA. 2013. Multiple sensors ensure guide strand selection in human RNAi pathways. RNA 19: 639-648.

Nunez RD, Budt M, Saenger S, Paki K, Arnold U, Sadewasser A, Wolff T. 2018. The RNA helicase DDX6 associates with RIG-I to augment induction of antiviral signaling. Int J Mol Sci 19: 1877.

Odon V, Fros JJ, Goonawardane N, Dietrich I, Ibrahim A, Alshaikhahmed K, Nguyen D, Simmonds P. 2019. The role of ZAP and OAS3/RNAseL pathways in the attenuation of an RNA virus with elevated frequencies of CpG and UpA dinucleotides. Nucleic Acids Res 47: 8061-8083.

Onomoto K, Jogi M, Yoo JS, Narita R, Morimoto S, Takemura A, Sambhara S, Kawaguchi A, Osari S, Nagata $K$ et al. 2012. Critical role of an antiviral stress granule containing RIG-I and PKR in viral detection and innate immunity. PLoS ONE 7: e43031.

Onomoto K, Onoguchi K, Yoneyama M. 2021. Regulation of RIG-I-like receptor-mediated signaling: interaction between host and viral factors. Cell Mol Immunol 18: 539-555.

Oshiumi H, Matsumoto M, Hatakeyama S, Seya T. 2009. Riplet/RNF135, a RING finger protein, ubiquitinates RIG-I to promote interferon-beta induction during the early phase of viral infection. J Biol Chem 284: 807-817.

Oshiumi H, Miyashita M, Inoue N, Okabe M, Matsumoto M, Seya T. 2010a. The ubiquitin ligase riplet is essential for RIG-I-dependent innate immune responses to RNA virus infection. Cell Host Microbe 8: 496-509.

Oshiumi H, Miyashita M, Matsumoto M, Seya T. 2013. A distinct role of Riplet-mediated K63-linked polyubiquitination of the RIG-I repressor domain in human antiviral innate immune responses. PLoS Pathog 9: e1003533.

Oshiumi H, Sakai K, Matsumoto M, Seya T. 2010b. DEAD/H BOX 3 (DDX3) helicase binds the RIG-I adaptor IPS-1 to up-regulate IFN- $\beta$-inducing potential. Eur J Immunol 40: 940-948.

Park H, Davies MV, Langland JO, Chang HW, Nam YS, Tartaglia J, Paoletti E, Jacobs BL, Kaufman RJ, Venkatesan S. 1994. TAR RNA-binding protein is an inhibitor of the interferon-induced protein kinase PKR. Proc Natl Acad Sci USA 91: 4713-4717.

Patel CV, Handy I, Goldsmith T, Patel RC. 2000. PACT, a stress-modulated cellular activator of interferon-induced double-stranded RNA-activated protein kinase, PKR. J Biol Chem 275: 37993-37998.

Patel RC, Sen GC. 1998. PACT, a protein activator of the interferon-induced protein kinase, PKR. EMBO J 17: 4379-4390. 
Pattabhi S, Knoll ML, Gale M, Loo Y-M. 2019. DHX15 Is a coreceptor for RLR signaling that promotes antiviral defense against rna virus infection. J Interferon Cytokine Res 39: 331-346.

Perdiguero B, Esteban M. 2009. The interferon system and vaccinia virus evasion mechanisms. J Interferon Cytokine Res 29: 581-598.

Pereira B, Le Borgne M, Chartier NT, Billaud M, Almeida R. 2013. MEX-3 proteins: recent insights on novel post-transcriptional regulators. Trends Biochem Sci 38: 477-479.

Pestal K, Funk CC, Snyder JM, Price ND, Treuting PM, Stetson DB. 2015. Isoforms of RNA-editing enzyme ADAR1 independently control nucleic acid sensor MDA5-driven autoimmunity and multi-organ development. Immunity 43: 933-944.

Pham AM, Santa Maria FG, Lahiri T, Friedman E, Marié IJ, Levy DE. 2016. PKR transduces MDA5dependent signals for type I IFN induction. PLoS Pathog 12: e1005489.

Pichlmair A, Lassnig C, Eberle CA, Gorna MW, Baumann CL, Burkard TR, Burckstummer T, Stefanovic A, Krieger S, Bennett KL et al. 2011. IFIT1 is an antiviral protein that recognizes 5'-triphosphate RNA. Nat Immunol 12: 624-630.

Pichlmair A, Schulz O, Tan CP, Naslund TI, Liljestrom P, Weber F, Reis e Sousa C. 2006. RIG-I-mediated antiviral responses to single-stranded RNA bearing 5'-phosphates. Science 314: 997-1001.

Pichlmair A, Schulz O, Tan CP, Rehwinkel J, Kato H, Takeuchi O, Akira S, Way M, Schiavo G, Reis E Sousa C. 2009. Activation of MDA5 requires higher-order RNA structures generated during virus infection. J Virol 83: 10761-10769.

Poeck H, Bscheider M, Gross O, Finger K, Roth S, Rebsamen M, Hannesschlager N, Schlee M, Rothenfusser S, Barchet $W$ et al. 2010. Recognition of RNA virus by RIG-I results in activation of CARD9 and inflammasome signaling for interleukin 1 beta production. Nat Immunol 11: 6369.

Poeck H, Ruland J. 2012. From virus to inflammation: mechanisms of RIG-I-induced IL-1beta production. Eur J Cell Biol 91: 59-64.

Qian L, Zuo Y, Deng W, Miao Y, Liu J, Yuan Y, Guo T, Zhang L, Jin J, Wang J et al. 2018. MCPIP1 is a positive regulator of type I interferons antiviral activity. Biochem Biophys Res Commun 498: 891-897.

Quicke KM, Kim KY, Horvath CM, Suthar MS. 2019. RNA helicase LGP2 negatively regulates RIG-I signaling by preventing TRIM25-mediated caspase activation and recruitment domain ubiquitination. J Interferon Cytokine Res 39: 669-683.

Quin J, Sedmik J, Vukic D, Khan A, Keegan LP, O'Connell MA. 2021. ADAR RNA modifications, the epitranscriptome and innate immunity. Trends Biochem Sci 46: 758-771.

Rebsamen M, Vazquez J, Tardivel A, Guarda G, Curran J, Tschopp J. 2011. NLRX1/NOD5 deficiency does not affect MAVS signalling. Cell Death Differ 18: 1387.

Rehwinkel J, Gack MU. 2020. RIG-I-like receptors: their regulation and roles in RNA sensing. Nat Rev Immunol 20: 537-551.

Rice GI, Kasher PR, Forte GM, Mannion NM, Greenwood SM, Szynkiewicz M, Dickerson JE, Bhaskar SS, Zampini M, Briggs TA et al. 2012. Mutations in ADAR1 cause Aicardi-Goutieres syndrome associated with a type I interferon signature. Nat Genet 44: 1243-1248.

Richt JA, García-Sastre A. 2009. Attenuated influenza virus vaccines with modified NS1 proteins. Curr Top Microbiol Immunol 333: 177-195.

Rodriguez KR, Bruns AM, Horvath CM. 2014. MDA5 and LGP2: accomplices and antagonists of antiviral signal transduction. J Virol 88: 8194-8200.

Rothenfusser S, Goutagny N, DiPerna G, Gong M, Monks BG, Schoenemeyer A, Yamamoto M, Akira S, Fitzgerald KA. 2005. The RNA helicase Lgp2 inhibits TLR-independent sensing of viral replication by retinoic acid-inducible gene-I. J Immunol 175: 5260-5268.

Ruan J, Cao Y, Ling T, Li P, Wu S, Peng D, Wang Y, Jia X, Chen S, Xu A et al. 2019. DDX23, an evolutionary conserved dsRNA sensor, participates in innate antiviral responses by pairing with TRIF or MAVS. Front Immunol 10: 2202. 
Runge S, Sparrer KMJ, Lässig C, Hembach K, Baum A, García-Sastre A, Söding J, Conzelmann KK, Hopfner KP. 2014. In vivo ligands of MDA5 and RIG-I in measles virus-infected vells. PLoS Pathog 10: e1004081.

Sabbah A, Chang TH, Harnack R, Frohlich V, Tominaga K, Dube PH, Xiang Y, Bose S. 2009. Activation of innate immune antiviral responses by Nod2. Nat Immunol 10: 1073-1080.

Saito T, Hirai R, Loo YM, Owen D, Johnson CL, Sinha SC, Akira S, Fujita T, Gale M, Jr. 2007. Regulation of innate antiviral defenses through a shared repressor domain in RIG-I and LGP2. Proc Natl Acad Sci U S A 104: 582-587.

Saito T, Owen DM, Jiang F, Marcotrigiano J, Gale M, Jr. 2008. Innate immunity induced by compositiondependent RIG-I recognition of hepatitis C virus RNA. Nature 454: 523-527.

Samanta M, Iwakiri D, Kanda T, Imaizumi T, Takada K. 2006. EB virus-encoded RNAs are recognized by RIG-I and activate signaling to induce type I IFN. EMBO J 25: 4207-4214.

Samir P, Kesavardhana S, Patmore DM, Gingras S, Malireddi RKS, Karki R, Guy CS, Briard B, Place DE, Bhattacharya A et al. 2019. DDX3X acts as a live-or-die checkpoint in stressed cells by regulating NLRP3 inflammasome. Nature 573: 590-594.

Sanchez David RY, Combredet C, Najburg V, Millot GA, Beauclair G, Schwikowski B, Léger T, Camadro JM, Jacob Y, Bellalou J et al. 2019. LGP2 binds to PACT to regulate RIG-I- and MDA5-mediated antiviral responses. Sci Signal 12: eaar3993.

Sanchez David RY, Combredet C, Sismeiro O, Dillies MA, Jagla B, Coppee JY, Mura M, Guerbois Galla $M$, Despres $P$, Tangy $F$ et al. 2016. Comparative analysis of viral RNA signatures on different RIG-I-like receptors. elife 5: e11275.

Sanchez JG, Sparrer KMJ, Chiang C, Reis RA, Chiang JJ, Zurenski MA, Wan Y, Gack MU, Pornillos O. 2018. TRIM25 Binds RNA to Modulate Cellular Anti-viral Defense. J Mol Biol 430: 5280-5293.

Sato S, Li K, Kameyama T, Hayashi T, Ishida Y, Murakami S, Watanabe T, lijima S, Sakurai Y, Watashi K et al. 2015. The RNA sensor RIG-I dually functions as an innate sensor and direct antiviral factor for hepatitis B virus. Immunity 42: 123-132.

Satoh T, Kato H, Kumagai Y, Yoneyama M, Sato S, Matsushita K, Tsujimura T, Fujita T, Akira S, Takeuchi O. 2010. LGP2 is a positive regulator of RIG-I- and MDA5-mediated antiviral responses. Proc Natl Acad Sci U S A 107: 1512-1517.

Schilling M, Bridgeman A, Gray N, Hertzog J, Hublitz P, Kohl A, Rehwinkel J. 2020. RIG-I Plays a dominant role in the induction of transcriptional changes in Zika virus-infected cells, which protect from virus-induced cell death. Cells 9: 1476.

Schlee M, Roth A, Hornung V, Hagmann CA, Wimmenauer V, Barchet W, Coch C, Janke M, Mihailovic $A$, Wardle $G$ et al. 2009. Recognition of 5' triphosphate by RIG-I helicase requires short blunt double-stranded RNA as contained in panhandle of negative-strand virus. Immunity 31: 25-34.

Schmidt A, Schwerd T, Hamm W, Hellmuth JC, Cui S, Wenzel M, Hoffmann FS, Michallet MC, Besch R, Hopfner KP et al. 2009. 5'-triphosphate RNA requires base-paired structures to activate antiviral signaling via RIG-I. Proc Natl Acad Sci U S A 106: 12067-12072.

Schnell G, Loo YM, Marcotrigiano J, Gale M, Jr. 2012. Uridine composition of the poly-U/UC tract of HCV RNA defines non-self recognition by RIG-I. PLoS Pathog 8: e1002839.

Schoggins JW. 2019. Interferon-stimulated genes: What do they all Do? Annu Rev Virol 6: 567-584.

Schoggins JW, Wilson SJ, Panis M, Murphy MY, Jones CT, Bieniasz P, Rice CM. 2011. A diverse range of gene products are effectors of the type I interferon antiviral response. Nature 472: 481-485.

Schuberth-Wagner C, Ludwig J, Bruder AK, Herzner AM, Zillinger T, Goldeck M, Schmidt T, SchmidBurgk JL, Kerber R, Wolter S et al. 2015. A Conserved Histidine in the RNA Sensor RIG-I Controls Immune Tolerance to N1-2'O-Methylated Self RNA. Immunity 43: 41-51.

Schulz O, Pichlmair A, Rehwinkel J, Rogers NC, Scheuner D, Kato H, Takeuchi O, Akira S, Kaufman RJ, Reis e Sousa C. 2010. Protein kinase R contributes to immunity against specific viruses by regulating interferon mRNA integrity. Cell Host Microbe 7: 354-361. 
Sen A, Pruijssers AJ, Dermody TS, Garcia-Sastre A, Greenberg HB. 2011. The early interferon response to rotavirus is regulated by PKR and depends on MAVS/IPS-1, RIG-I, MDA-5, and IRF3. $J$ Virol 85: 3717-3732.

Seo GJ, Kim C, Shin WJ, Sklan EH, Eoh H, Jung JU. 2018. TRIM56-mediated monoubiquitination of cGAS for cytosolic DNA sensing. Nat Commun 9: 613.

Shao J, Huang Q, Liu X, Di D, Liang Y, Ly H. 2018. Arenaviral nucleoproteins suppress PACT-induced augmentation of RIG-I Function to inhibit type I interferon production. J Virol 92: e00482-18.

Shaw AE, Rihn SJ, Mollentze N, Wickenhagen A, Stewart DG, Orton RJ, Kuchi S, Bakshi S, Collados MR, Turnbull ML et al. 2021. The antiviral state has shaped the CpG composition of the vertebrate interferome to avoid self-targeting. PLoS Biol 19: e3001352.

Shen Y, Li NL, Wang J, Liu B, Lester S, Li K. 2012. TRIM56 is an essential component of the TLR3 antiviral signaling pathway. J Biol Chem 287: 36404-36413.

Siu KL, Yeung ML, Kok KH, Yuen KS, Kew C, Lui PY, Chan CP, Tse H, Woo PC, Yuen KY et al. 2014. Middle east respiratory syndrome coronavirus 4 a protein is a double-stranded RNA-binding protein that suppresses PACT-induced activation of RIG-I and MDA5 in the innate antiviral response. J Virol 88: 4866-4876.

Siu KL, Yuen KS, Castano-Rodriguez C, Ye ZW, Yeung ML, Fung SY, Yuan S, Chan CP, Yuen KY, Enjuanes $L$ et al. 2019. Severe acute respiratory syndrome coronavirus ORF3a protein activates the NLRP3 inflammasome by promoting TRAF3-dependent ubiquitination of ASC. FASEB $J 33$ : 8865-8877.

Slater L, Bartlett NW, Haas JJ, Zhu J, Message SD, Walton RP, Sykes A, Dahdaleh S, Clarke DL, Belvisi MG et al. 2010. Co-ordinated role of TLR3, RIG-I and MDA5 in the innate response to rhinovirus in bronchial epithelium. PLoS Pathog 6: e1001178.

Solis M, Nakhaei P, Jalalirad M, Lacoste J, Douville R, Arguello M, Zhao T, Laughrea M, Wainberg MA, Hiscott J. 2011. RIG-I-mediated antiviral signaling is inhibited in HIV-1 infection by a proteasemediated sequestration of RIG-I. J Virol 85: 1224-1236.

Song B, Chen Y, Liu X, Yuan F, Tan EYJ, Lei Y, Song N, Han Y, Pascal BD, Griffin PR, Luo C, Wu B, Luo D, Zheng J. 2021. Ordered assembly of the cytosolic RNA-sensing MDA5-MAVS signaling complex via binding to unanchored K63-linked poly-ubiquitin chains. Immunity 54: 2218-2230.

Soonthornvacharin S, Rodriguez-Frandsen A, Zhou Y, Galvez F, Huffmaster NJ, Tripathi S, Balasubramaniam VR, Inoue A, de Castro E, Moulton H et al. 2017. Systems-based analysis of RIG-I-dependent signalling identifies KHSRP as an inhibitor of RIG-I receptor activation. Nat Microbiol 2: 17022.

Stavrou S, Aguilera AN, Blouch K, Ross SR. 2018. DDX41 recognizes RNA/DNA retroviral reverse transcripts and is critical for in vivo control of murine leukemia virus infection. mBio 9: e0092318.

Su C, Zhang J, Zheng C. 2015. Herpes simplex virus 1 UL41 protein abrogates the antiviral activity of hZAP by degrading its mRNA. Virol J 12: 203.

Sugimoto N, Mitoma H, Kim T, Hanabuchi S, Liu Y-J. 2014. Helicase proteins DHX29 and RIG-I cosense cytosolic nucleic acids in the human airway system. Proc Natl Acad Sci U S A 111: 7747-7752.

Sun X, Feng W, Guo Y, Wang Q, Dong C, Zhang M, Guan Z, Duan M. 2018. MCPIP1 attenuates the innate immune response to influenza A virus by suppressing RIG-I expression in lung epithelial cells. J Med Virol 90: 204-211.

Takaoka A, Wang Z, Choi MK, Yanai H, Negishi H, Ban T, Lu Y, Miyagishi M, Kodama T, Honda K et al. 2007. DAI (DLM-1/ZBP1) is a cytosolic DNA sensor and an activator of innate immune response. Nature 448: 501-505.

Tang Q, Wang X, Gao G. 2017. The short form of the zinc finger antiviral protein inhibits influenza A virus protein expression and is antagonized by the virus-encoded NS1. J Viro/ 91: e01909-16.

Taniguchi N, Kawakami Y, Maruyama I, Lotz M. 2018. HMGB proteins and arthritis. Hum Cell 31: 1-9.

Taschuk F, Cherry S. 2020. DEAD-Box Helicases: sensors, regulators, and effectors for antiviral defense. Viruses 12: 181. 
Tattoli I, Carneiro LA, Jehanno M, Magalhaes JG, Shu Y, Philpott DJ, Arnoult D, Girardin SE. 2008. NLRX1 is a mitochondrial NOD-like receptor that amplifies NF-KB and JNK pathways by inducing reactive oxygen species production. EMBO Rep 9: 293-300.

Tawaratsumida K, Phan V, Hrincius ER, High AA, Webby R, Redecke V, Hacker H. 2014. Quantitative proteomic analysis of the influenza A virus nonstructural proteins NS1 and NS2 during natural cell infection identifies PACT as an NS1 target protein and antiviral host factor. J Viro/ 88: 90389048.

Terenzi F, Saikia P, Sen GC. 2008. Interferon-inducible protein, P56, inhibits HPV DNA replication by binding to the viral protein E1. EMBO J 27: 3311-3321.

Thapa RJ, Ingram JP, Ragan KB, Nogusa S, Boyd DF, Benitez AA, Sridharan H, Kosoff R, Shubina M, Landsteiner VJ et al. 2016. DAl senses influenza A virus genomic RNA and activates RIPK3dependent cell death. Cell Host Microbe 20: 674-681.

Thoresen D, Wang W, Galls D, Guo R, Xu L, Pyle AM. 2021. The molecular mechanism of RIG-I activation and signaling. Immunol Rev doi: 10.1111/imr.13022.

Tremblay N, Baril M, Chatel-Chaix L, Es-Saad S, Park AY, Koenekoop RK, Lamarre D. 2016. Spliceosome SNRNP200 promotes viral RNA sensing and IRF3 activation of antiviral response. PLoS Pathog 12: e1005772.

Tsuchida T, Zou J, Saitoh T, Kumar H, Abe T, Matsuura Y, Kawai T, Akira S. 2010. The ubiquitin ligase TRIM56 regulates innate immune responses to intracellular double-stranded DNA. Immunity 33: 765-776.

Uchikawa E, Lethier M, Malet H, Brunel J, Gerlier D, Cusack S. 2016. Structural analysis of dsRNA binding to anti-viral pattern recognition receptors LGP2 and MDA5. Mol Cell 62: 586-602.

Urano T, Usui T, Takeda S, Ikeda K, Okada A, Ishida Y, Iwayanagi T, Otomo J, Ouchi Y, Inoue S. 2009. TRIM44 interacts with and stabilizes terf, a TRIM ubiquitin E3 ligase. Biochem Biophys Res Commun 383: 263-268.

van der Lee R, Feng Q, Langereis MA, Ter Horst R, Szklarczyk R, Netea MG, Andeweg AC, van Kuppeveld FJ, Huynen MA. 2015. Integrative genomics-based discovery of novel regulators of the innate antiviral response. PLoS Comput Biol 11: e1004553.

van Gent M, Sparrer KMJ, Gack MU. 2018. TRIM proteins and their roles in antiviral host defenses. Annu Rev Virol 5: 385-405.

Vaughn LS, Chukwurah E, Patel RC. 2021. Opposite actions of two dsRNA-binding proteins PACT and TRBP on RIG-I mediated signaling. Biochem J 478: 493-510.

Vavassori S, Chou J, Faletti LE, Haunerdinger V, Opitz L, Joset P, Fraser CJ, Prader S, Gao X, Schuch LA et al. 2021. Multisystem inflammation and susceptibility to viral infections in human ZNFX1 deficiency. J Allergy Clin Immunol 148: 381-393.

Vaysburd M, Watkinson RE, Cooper H, Reed M, O'Connell K, Smith J, Cruickshanks J, James LC. 2013. Intracellular antibody receptor TRIM21 prevents fatal viral infection. Proc Natl Acad Sci U S A 110: 12397-12401.

Visser LJ, Medina GN, Rabouw HH, de Groot RJ, Langereis MA, de Los Santos T, van Kuppeveld FJM. 2019. Foot-and-mouth disease virus leader protease cleaves G3BP1 and G3BP2 and inhibits stress granule formation. J Virol 93: e00922-18.

Wang G, Kouwaki T, Okamoto M, Oshiumi H. 2019a. Attenuation of the innate immune response against viral infection due to ZNF598-promoted binding of FAT10 to RIG-I. Cell Rep 28: 19611970 e1964.

Wang J, Liu B, Wang N, Lee YM, Liu C, Li K. 2011. TRIM56 is a virus- and interferon-inducible E3 ubiquitin ligase that restricts pestivirus infection. J Virol 85: 3733-3745.

Wang P, Zheng M, Lau SY, Chen P, Mok BW, Liu S, Liu H, Huang X, Cremin CJ, Song W, Chen Y, Wong YC, Huang H, To KK, Chen Z, Xia N, Yuen KY, Chen H. 2019b. Generation of DelNS1 influenza viruses: a strategy for optimizing live attenuated influenza vaccines. mBio 10: e02180-19.

Wang P, Zhu S, Yang L, Cui S, Pan W, Jackson R, Zheng Y, Rongvaux A, Sun Q, Yang G et al. 2015. NIrp6 regulates intestinal antiviral innate immunity. Science 350: 826-830. 
1904

1905

1906

1907

1908

1909

1910

1911

1912

1913

1914

1915

1916

1917

1918

1919

1920

1921

1922

1923

1924

1925

1926

1927

1928

1929

1930

1931

1932

1933

1934

1935

1936

1937

1938

1939

1940

1941

1942

1943

1944

1945

1946

1947

1948

1949

1950

1951

1952

Wang Q, Nagarkar DR, Bowman ER, Schneider D, Gosangi B, Lei J, Zhao Y, McHenry CL, Burgens RV, Miller DJ et al. 2009. Role of double-stranded RNA pattern recognition receptors in rhinovirusinduced airway epithelial cell responses. J Immunol 183: 6989-6997.

Wang X, Jiang W, Yan Y, Gong T, Han J, Tian Z, Zhou R. 2014. RNA viruses promote activation of the NLRP3 inflammasome through a RIP1-RIP3-DRP1 signaling pathway. Nat Immunol 15: 11261133.

Wang Y, Yuan S, Jia X, Ge Y, Ling T, Nie M, Lan X, Chen S, Xu A. 2019c. Mitochondria-localised ZNFX1 functions as a dsRNA sensor to initiate antiviral responses through MAVS. Nat Cell Biol 21: 1346-1356.

Watkinson RE, McEwan WA, Tam JC, Vaysburd M, James LC. 2015. TRIM21 promotes CGAS and RIG-I Sensing of viral genomes during infection by antibody-opsonized virus. PLoS Pathog 11: e1005253.

Williams FP, Haubrich K, Perez-Borrajero C, Hennig J. 2019. Emerging RNA-binding roles in the TRIM family of ubiquitin ligases. Biol Chem 400: 1443-1464.

Wilson RC, Tambe A, Kidwell MA, Noland CL, Schneider CP, Doudna JA. 2015. Dicer-TRBP complex formation ensures accurate mammalian microRNA biogenesis. Mol Cell 57: 397-407.

Wong LY, Lui PY, Jin DY. 2016. A molecular arms race between host innate antiviral response and emerging human coronaviruses. Virol $\operatorname{Sin}$ 31: 12-23.

Wu SF, Xia L, Shi XD, Dai YJ, Zhang WN, Zhao JM, Zhang W, Weng XQ, Lu J, Le HY et al. 2020. RIG-I regulates myeloid differentiation by promoting TRIM25-mediated ISGylation. Proc Natl Acad Sci U S A 117: 14395-14404.

Xian H, Yang S, Jin S, Zhang Y, Cui J. 2020. LRRC59 modulates type I interferon signaling by restraining the SQSTM1/p62-mediated autophagic degradation of pattern recognition receptor DDX58/RIG-I. Autophagy 16: 408-418.

Xiao G, Yang Q, Bao Z, Mao H, Zhang Y, Lin S. 2020. Expression of tripartite motif-containing 44 and its prognostic and clinicopathological value in human malignancies:a meta-analysis. BMC Cancer 20: 525 .

Xie L, Lu B, Zheng Z, Miao Y, Liu Y, Zhang Y, Zheng C, Ke X, Hu Q, Wang H. 2018a. The 3C protease of enterovirus A71 counteracts the activity of host zinc-finger antiviral protein (ZAP). J Gen Virol 99: 73-85.

Xie Q, Chen S, Tian R, Huang X, Deng R, Xue B, Qin Y, Xu Y, Wang J, Guo M et al. 2018b. Long noncoding RNA ITPRIP-1 positively regulates the innate immune response through promotion of oligomerization and activation of MDA5. J Virol 92: e00507-18.

Xing J, Wang S, Lin R, Mossman KL, Zheng C. 2012. Herpes simplex virus 1 tegument protein US11 downmodulates the RLR signaling pathway via direct interaction with RIG-I and MDA-5. J Virol 86: 3528-3540.

Xing J, Ly H, Liang Y. 2015. The Z proteins of pathogenic but not nonpathogenic arenaviruses inhibit RIG-I-like receptor-dependent interferon production. J Virol 89: 2944-2955.

Xing J, Zhang A, Du Y, Fang M, Minze L, Liu YJ, Li XC, Zhang Z. 2021a. Identification of poly(ADP-ribose) polymerase 9 (PARP9) as a noncanonical sensor for RNA virus in dendritic cells. Nat Commun 12: 2681.

Xing J, Zhou X, Fang M, Zhang E, Minze LJ, Zhang Z. 2021b. DHX15 is required to control RNA virusinduced intestinal inflammation. Cell Rep 35: 109205.

Xu J, Mercado-Lopez X, Grier JT, Kim WK, Chun LF, Irvine EB, Del Toro Duany Y, Kell A, Hur S, Gale M, Jr. et al. 2015. Identification of a natural viral RNA motif that optimizes sensing of viral RNA by RIG-I. mBio 6: e01265-01215.

Xue B, Li H, Guo M, Wang J, Xu Y, Zou X, Deng R, Li G, Zhu H. 2018. TRIM21 promotes innate immune response to RNA viral infection through Lys27-linked polyubiquitination of MAVS. J Virol 92: e00321-18. 
Yanai H, Ban T, Wang Z, Choi MK, Kawamura T, Negishi H, Nakasato M, Lu Y, Hangai S, Koshiba R et al. 2009. HMGB proteins function as universal sentinels for nucleic-acid-mediated innate immune responses. Nature 462: 99-103.

Yang B, Wang J, Wang Y, Zhou H, Wu X, Tian Z, Sun B. 2013. Novel function of Trim44 promotes an antiviral response by stabilizing VISA. J Immunol 190: 3613-3619.

Yang D, Li NL, Wei D, Liu B, Guo F, Elbahesh H, Zhang Y, Zhou Z, Chen GY, Li K. 2019. The E3 ligase TRIM56 is a host restriction factor of Zika virus and depends on its RNA-binding activity but not miRNA regulation, for antiviral function. PLoS Negl Trop Dis 13: e0007537.

Yang L, Wang L, Ketkar H, Ma J, Yang G, Cui S, Geng T, Mordue DG, Fujimoto T, Cheng G et al. 2018. UBXN3B positively regulates STING-mediated antiviral immune responses. Nat Commun 9: 2329.

Yang S, Deng P, Zhu Z, Zhu J, Wang G, Zhang L, Chen AF, Wang T, Sarkar SN, Billiar TR et al. 2014. Adenosine deaminase acting on RNA 1 limits RIG-I RNA detection and suppresses IFN production responding to viral and endogenous RNAs. J Immunol 193: 3436-3445.

Yang W, Li D, Ru Y, Bai J, Ren J, Zhang J, Li L, Liu X, Zheng H. 2020. Foot-and-mouth disease virus $3 A$ protein causes upregulation of autophagy-related protein LRRC25 to inhibit the G3BP1mediated RIG-like helicase-signaling pathway. J Virol 94: e02086-19.

Yoneyama M, Kikuchi M, Natsukawa T, Shinobu N, Imaizumi T, Miyagishi M, Taira K, Akira S, Fujita T. 2004. The RNA helicase RIG-I has an essential function in double-stranded RNA-induced innate antiviral responses. Nat Immunol 5: 730-737.

Yoo J-S, Takahasi K, Ng CS, Ouda R, Onomoto K, Yoneyama M, Lai JC, Lattmann S, Nagamine Y, Matsui T et al. 2014. DHX36 enhances RIG-I signaling by facilitating PKR-mediated antiviral stress granule formation. PLoS Pathog 10: e1004012.

Yount JS, Gitlin L, Moran TM, Lopez CB. 2008. MDA5 participates in the detection of paramyxovirus infection and is essential for the early activation of dendritic cells in response to Sendai Virus defective interfering particles. J Immunol 180: 4910-4918.

Zang R, Lian H, Zhong X, Yang Q, Shu HB. 2020. ZCCHC3 modulates TLR3-mediated signaling by promoting recruitment of TRIF to TLR3. J Mol Cell Biol 12: 251-262.

Zeng W, Sun L, Jiang X, Chen X, Hou F, Adhikari A, Xu M, Chen ZJ. 2010. Reconstitution of the RIG-I pathway reveals a signaling role of unanchored polyubiquitin chains in innate immunity. Cell 141: 315-330.

Zhang R, Cheng M, Liu B, Yuan M, Chen D, Wang Y, Wu Z. 2021. DEAD-Box Helicase DDX6 Facilitated RIG-I-Mediated Type-I Interferon Response to EV71 Infection. Front Cell Infect Microbiol 11: 725392.

Zhang Z, Kim T, Bao M, Facchinetti V, Sung, Amir, Qin J, Cheng G, Liu Y-J. 2011a. DDX1, DDX21, and DHX36 helicases form a complex with the adaptor molecule TRIF to sense dsRNA in Dendritic Cells. Immunity 34: 866-878.

Zhang Z, Yuan B, Lu N, Facchinetti V, Liu YJ. 2011b. DHX9 pairs with IPS-1 to sense double-stranded RNA in myeloid dendritic cells. J Immunol 187: 4501-4508.

Zhao Y, Karijolich J. 2019. Know Thyself: RIG-I-Like Receptor Sensing of DNA Virus Infection. J Viro/ 93.

Zhao Y, Song Z, Bai J, Liu X, Nauwynck H, Jiang P. 2019. ZAP, a CCCH-type zinc finger protein, inhibits porcine reproductive and respiratory syndrome virus replication and interacts with viral Nsp9. J Virol 93: e00001-19.

Zhao Y, Song Z, Bai J, Liu X, Nauwynck H, Jiang P. 2020. Porcine reproductive and respiratory syndrome virus Nsp4 cleaves ZAP to antagonize its antiviral activity. Vet Microbiol 250: 108863.

Zhao Y, Ye X, Dunker W, Song Y, Karijolich J. 2018. RIG-I like receptor sensing of host RNAs facilitates the cell-intrinsic immune response to KSHV infection. Nat Commun 9: 4841.

Zheng C. 2021. The emerging roles of NOD-like receptors in antiviral innate immune signaling pathways. Int J Biol Macromol 169: 407-413.

Zheng M, Karki R, Vogel P, Kanneganti TD. 2020. Caspase-6 is a key regulator of innate immunity, inflammasome activation, and host defense. Cell 181: 674-687.e13. 
2030

2031

2032

2033

2034

Zheng X, Wang X, Tu F, Wang Q, Fan Z, Gao G. 2017. TRIM25 is required for the antiviral activity of zinc finger antiviral protein. J Virol 91: e00088-17.

Zhong FL, Mamai O, Sborgi L, Boussofara L, Hopkins R, Robinson K, Szeverenyi I, Takeichi T, Balaji R, Lau A et al. 2016. Germline NLRP1 mutations cause skin inflammatory and cancer susceptibility syndromes via inflammasome activation. Cell 167: 187-202.e17.

Zhong X, Feng L, Xu WH, Wu X, Ding YD, Zhou Y, Lei CQ, Shu HB. 2020a. The zinc-finger protein ZFYVE1 modulates TLR3-mediated signaling by facilitating TLR3 ligand binding. Cell Mol Immunol 17: 741-752.

Zhong X, Feng L, Zang R, Lei CQ, Yang Q, Shu HB. 2020b. ZFYVE1 negatively regulates MDA5- but not RIG-I-mediated innate antiviral response. PLoS Pathog 16: e1008457.

Zhou L, Azfer A, Niu J, Graham S, Choudhury M, Adamski FM, Younce C, Binkley PF, Kolattukudy PE. 2006. Monocyte chemoattractant protein-1 induces a novel transcription factor that causes cardiac myocyte apoptosis and ventricular dysfunction. Circ Res 98: 1177-1185.

Zhu J, Zhang Y, Ghosh A, Cuevas RA, Forero A, Dhar J, Ibsen MS, Schmid-Burgk JL, Schmidt T, Ganapathiraju MK et al. 2014. Antiviral activity of human OASL protein is mediated by enhancing signaling of the RIG-I RNA sensor. Immunity 40: 936-948.

Zhu Q, Tan P, Li Y, Lin M, Li C, Mao J, Cui J, Zhao W, Wang HY, Wang R-F. 2018. DHX29 functions as an RNA co-sensor for MDA5-mediated EMCV-specific antiviral immunity. PLoS Pathog 14: e1006886.

Zhu S, Ding S, Wang P, Wei Z, Pan W, Palm NW, Yang Y, Yu H, Li HB, Wang G et al. 2017. Nlrp9b inflammasome restricts rotavirus infection in intestinal epithelial cells. Nature 546: 667-670.

Zhu Y, Chen G, Lv F, Wang X, Ji X, Xu Y, Sun J, Wu L, Zheng YT, Gao G. 2011. Zinc-finger antiviral protein inhibits HIV-1 infection by selectively targeting multiply spliced viral mRNAs for degradation. Proc Natl Acad Sci U S A 108: 15834-15839.

Zou W, Zhang DE. 2006. The interferon-inducible ubiquitin-protein isopeptide ligase (E3) EFP also functions as an ISG15 E3 ligase. J Biol Chem 281: 3989-3994.

Züst R, Cervantes-Barragan L, Habjan M, Maier R, Neuman BW, Ziebuhr J, Szretter KJ, Baker SC, Barchet W, Diamond MS et al. 2011. Ribose 2'-O-methylation provides a molecular signature for the distinction of self and non-self mRNA dependent on the RNA sensor Mda5. Nat Immunol 12: 137-143. 
2037 FIGURE 1. Cytoplasmic RNA sensors. Sensors and their downstream effectors are shown. RLRs

2038 are in yellow. Non-RLR DExD/H-box helicases are in pink. NLRs are in green. Other sensors are

2039 in blue. Stimulatory and inhibitory actions are highlighted by arrows and stop signs, 2040 respectively.

FIGURE 2. RNA-binding protein partners of cytoplasmic RNA sensors. RLRs are in yellow. TRIM 2043 proteins are in blue. PACT, TRBP and other RNA binding proteins are in dark blue. Zinc finger 2044 proteins are in pink. TBK1/IKKe are in green. IRF3 and NF-KB are in red. Stimulatory and 2045 inhibitory actions are highlighted by arrows and stop signs, respectively. 
$\begin{array}{cccc}\text { If } & \text { Inflammasome } \\ \text { activation } & \begin{array}{c}\text { Programmed } \\ \text { cell death }\end{array} & \begin{array}{c}\text { independent } \\ \text { mechanism }\end{array}\end{array}$

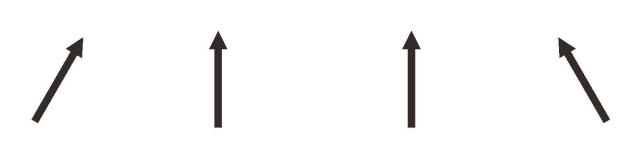

FADD/RIP1 TBK1

$\frac{T}{\uparrow}$

TRIF MAVS<smiles>[3H][TeH]</smiles>

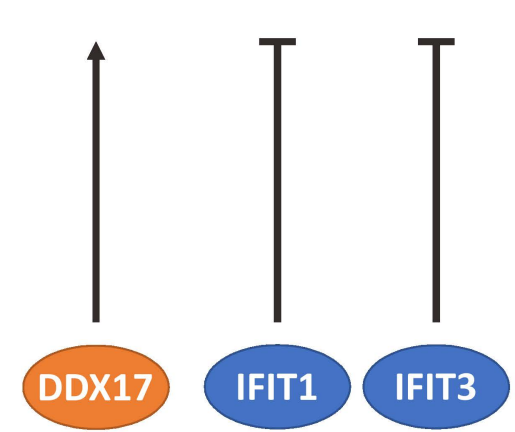

$\uparrow$

DDX21 DHX36

$\uparrow \uparrow \uparrow$

dsRNA CDOOOX

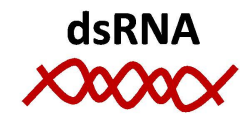

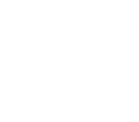

$\uparrow \uparrow$<smiles>C=CCC</smiles>

$\uparrow$<smiles>CCC</smiles>

dsRNA XOODO

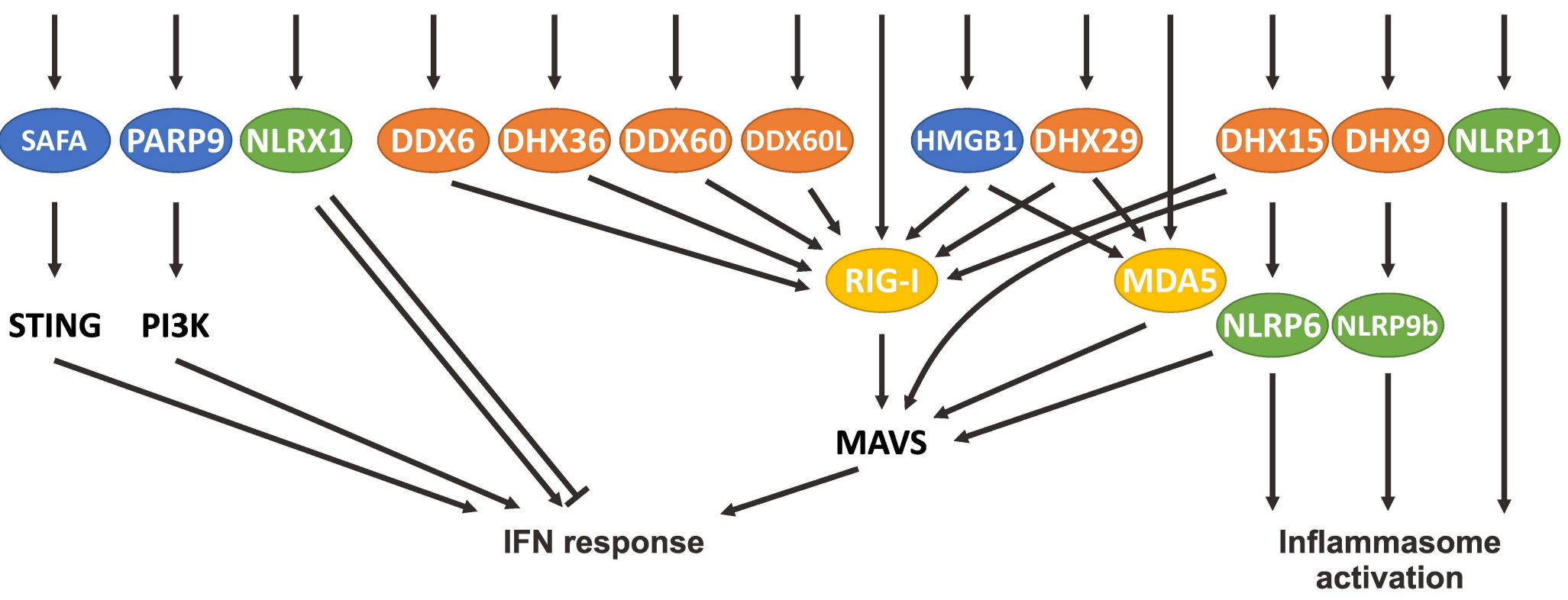

dsRNA CDOOX
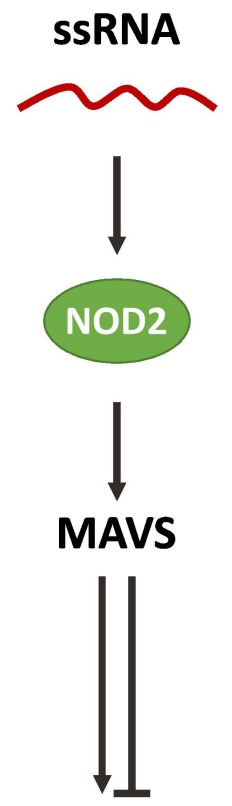

IFN response
RNA/DNA

hybrids

xoox

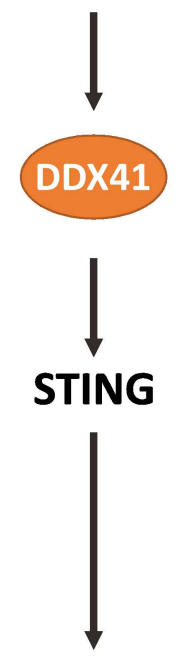

IFN response

Figure 1 


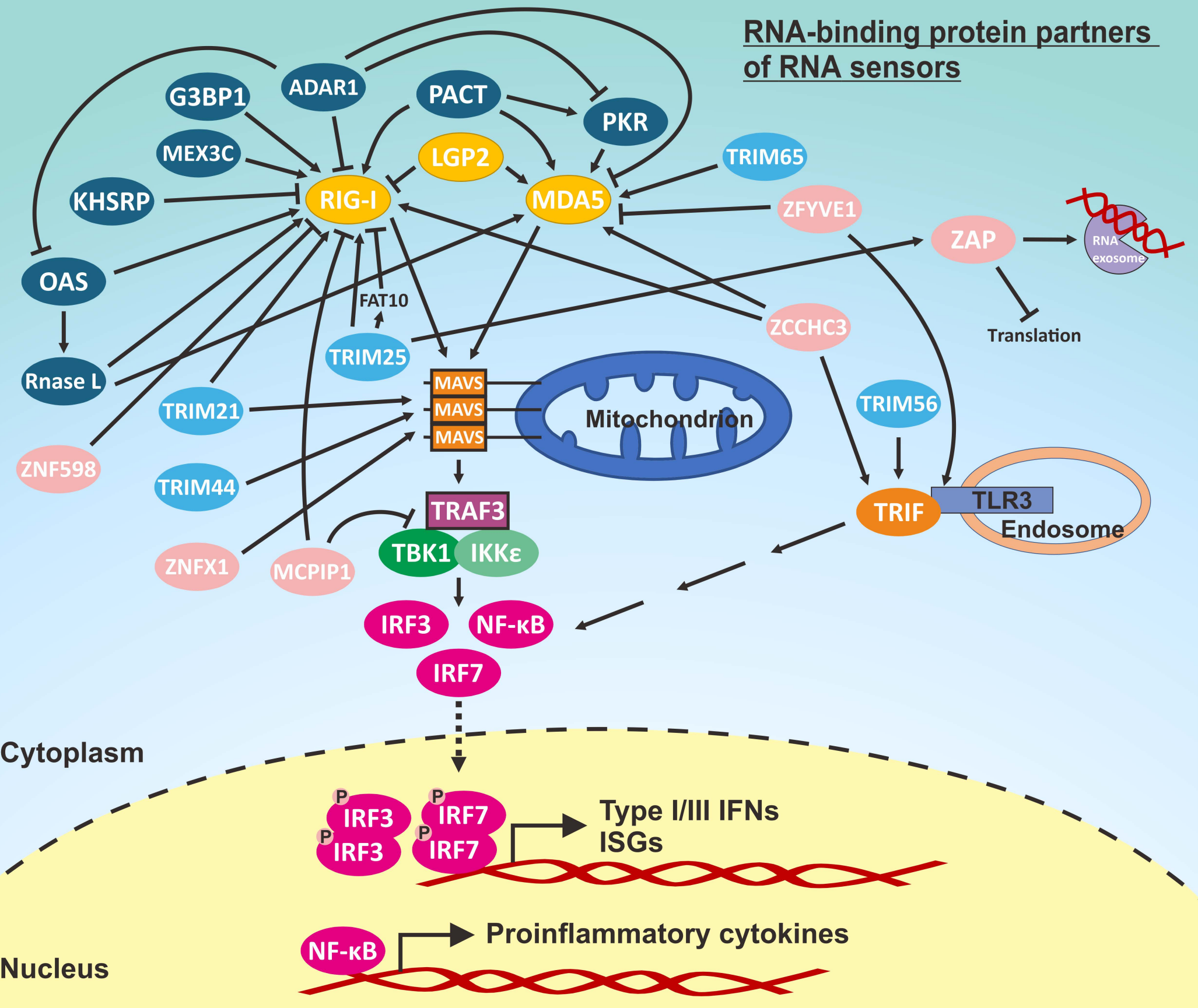

Figure 2 


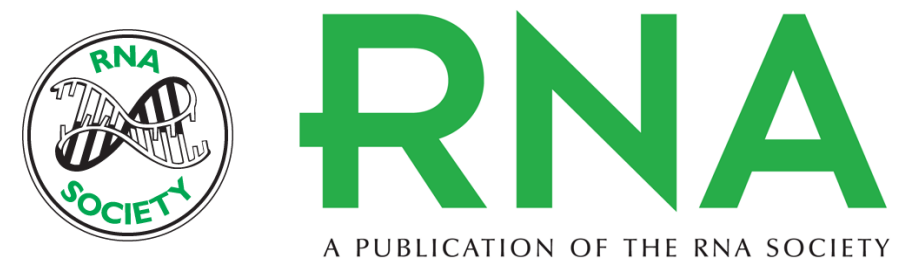

\title{
Cytoplasmic RNA sensors and their interplay with RNA-binding partners in innate antiviral response: Theme and variations
}

\author{
Chi-Ping Chan and Dong-Yan Jin \\ RNA published online January 14, 2022
}

\section{$\mathbf{P}<\mathbf{P} \quad$ Published online January 14, 2022 in advance of the print journal.}

Accepted Peer-reviewed and accepted for publication but not copyedited or typeset; accepted

Manuscript manuscript is likely to differ from the final, published version.

Open Access Freely available online through the RNA Open Access option.

Creative This article, published in RNA, is available under a Creative Commons License

Commons (Attribution-NonCommercial 4.0 International), as described at

License http://creativecommons.org/licenses/by-nc/4.0/.

Email Alerting Receive free email alerts when new articles cite this article - sign up in the box at the Service top right corner of the article or click here.

Advance online articles have been peer reviewed and accepted for publication but have not yet appeared in the paper journal (edited, typeset versions may be posted when available prior to final publication). Advance online articles are citable and establish publication priority; they are indexed by PubMed from initial publication. Citations to Advance online articles must include the digital object identifier (DOIs) and date of initial publication.

To subscribe to RNA go to:

http://rnajournal.cshlp.org/subscriptions 